\title{
Lymphocyte adaptor protein LNK deficiency exacerbates hypertension and end-organ inflammation
}

\author{
Mohamed A. Saleh,, ${ }^{1,2}$ William G. McMaster, ${ }^{1}$ Jing Wu, ${ }^{1}$ Allison E. Norlander, ${ }^{1}$ Samuel A. Funt,, ${ }^{3,4}$ Salim R. Thabet, ${ }^{1,3}$ \\ Annet Kirabo, ${ }^{1}$ Liang Xiao, ${ }^{1}$ Wei Chen, ${ }^{1}$ Hana A. Itani,, ${ }^{1}$ Danielle Michell, ${ }^{1}$ Tianxiao Huan,, ${ }^{5,6}$ Yahua Zhang, ${ }^{1}$ \\ Satoshi Takaki, ${ }^{7}$ Jens Titze, ${ }^{1}$ Daniel Levy, ${ }^{5,6}$ David G. Harrison, ${ }^{1}$ and Meena S. Madhur ${ }^{1}$ \\ 'Department of Medicine, Division of Clinical Pharmacology, Vanderbilt University, Nashville, Tennessee, USA. ²Department of Pharmacology and Toxicology, Faculty of Pharmacy, Mansoura University, \\ Mansoura, Egypt. ${ }^{3}$ Department of Medicine, Emory University, Atlanta, Georgia, USA. ${ }^{4}$ Department of Medicine, Memorial Sloan Kettering Cancer Center, New York, New York, USA. \\ ${ }^{5}$ The National Heart, Lung, and Blood Institute's Framingham Heart Study, Framingham, Massachusetts, USA. ${ }^{6}$ The Population Sciences Branch and the Division of Intramural Research, \\ National Heart, Lung, and Blood Institute, Bethesda, Maryland, USA. Department of Immune Regulation, Research Institute, National Center for Global Health and Medicine, Tokyo, Japan.
}

\begin{abstract}
The lymphocyte adaptor protein LNK (also known as SH2B3) is primarily expressed in hematopoietic and endothelial cells, where it functions as a negative regulator of cytokine signaling and cell proliferation. Single-nucleotide polymorphisms in the gene encoding LNK are associated with autoimmune and cardiovascular disorders; however, it is not known how LNK contributes to hypertension. Here, we determined that loss of LNK exacerbates angiotensin II-induced (Ang II-induced) hypertension and the associated renal and vascular dysfunction. At baseline, kidneys from Lnk ${ }^{-/-}$mice exhibited greater levels of inflammation, oxidative stress, and glomerular injury compared with WT animals, and these parameters were further exacerbated by Ang II infusion. Aortas from Lnk ${ }^{-1-}$ mice exhibited enhanced inflammation, reduced nitric oxide levels, and impaired endothelial-dependent relaxation. Bone marrow transplantation studies demonstrated that loss of LNK in hematopoietic cells is primarily responsible for the observed renal and vascular inflammation and predisposition to hypertension. Ang II infusion increased IFN- $\gamma$-producing CD8 ${ }^{+} \mathrm{T}$ cells in the spleen and kidneys of $\mathrm{Lnk}^{-/-}$mice compared with WT mice. Moreover, IFN- $\gamma$ deficiency resulted in blunted hypertension in response to Ang II infusion. Together, these results suggest that LNK is a potential therapeutic target for hypertension and its associated renal and vascular sequela.
\end{abstract}

\section{Introduction}

Hypertension is a leading cause of cardiovascular disease morbidity and mortality worldwide and a major risk factor for stroke, myocardial infarction, heart failure, and chronic kidney disease. Unfortunately, despite decades of research, the pathogenesis of essential hypertension is poorly understood and blood pressure (BP) control remains suboptimal in the general population (1). Epidemiological studies demonstrate that BP has a substantial heritable component, with estimates of heritability ranging from $33 \%$ to $57 \%(2-4)$. In an attempt to elucidate the genetic components of hypertension, GWAS have identified numerous loci harboring common genetic variants or SNPs associated with blood pressure. A missense mutation at position 262 (R262W) of LNK (SNP rs3184504) was found in prior GWAS to be associated with many autoimmune and cardiovascular disorders, including type 1 diabetes, celiac disease, hypercholesterolemia, myocardial infarction, and hypertension (5).

LNK is a member of the SH2B family of adaptor proteins, which are implicated in the integration and regulation of multiple signaling events. Expressed primarily in hematopoietic cells and endothelial cells, LNK functions as a negative regulator of hematopoiesis and endothelial cell signaling. But how and in which cell types LNK functions to regulate BP is unknown.

Conflict of interest: The authors have declared that no conflict of interest exists Submitted: March 25, 2014; Accepted: January 2, 2015

Reference information: / Clin Invest. 2015;125(3):1189-1202. doi:10.1172/JCI76327.
While the endothelium is certainly an important player, the immune system is emerging as a key contributor to hypertension and its associated renal and vascular dysfunction. Current evidence indicates that $\mathrm{T}$ cells and monocytes/macrophages are activated, infiltrate the kidney and perivascular sites, and release cytokines, such as IL-17A, IL-6, and TNF- $\alpha$, that affect vascular function and promote renal sodium retention (6-11). Mice lacking $\mathrm{T}$ cells, monocytes, or IL-17A exhibit blunted hypertension and inflammation in response to various hypertensive stimuli (6-8).

In the current study, we sought to determine the effect of LNK on hypertension and its associated renal/vascular inflammation and dysfunction. We found that loss of LNK markedly enhances inflammation, predisposing to hypertension, endothelial dysfunction, oxidative stress, and renal dysfunction. Using bone marrow transplantation (BMT) studies, we show that the predominant effect of LNK on BP is through the hematopoietic compartment, further emphasizing the importance of the immune system in hypertension. Importantly, we identify IFN- $\gamma$ producing $\mathrm{CD} 8^{+} \mathrm{T}$ cells as key players in this process. Lnk-deficient mice have increased splenic T cell production of IFN- $\gamma$ and markedly increased numbers of IFN- $\gamma$-producing $\mathrm{CD}^{+} \mathrm{T}$ cells in the spleen and kidney in response to angiotensin II (Ang II) infusion. Furthermore, we show that IFN- $\gamma$ deficiency protects against Ang II-induced hypertension. Taken together, these data demonstrate that LNK (SH2B3) may serve as a therapeutic target for hypertension and its associated renal and vascular dysfunction. 

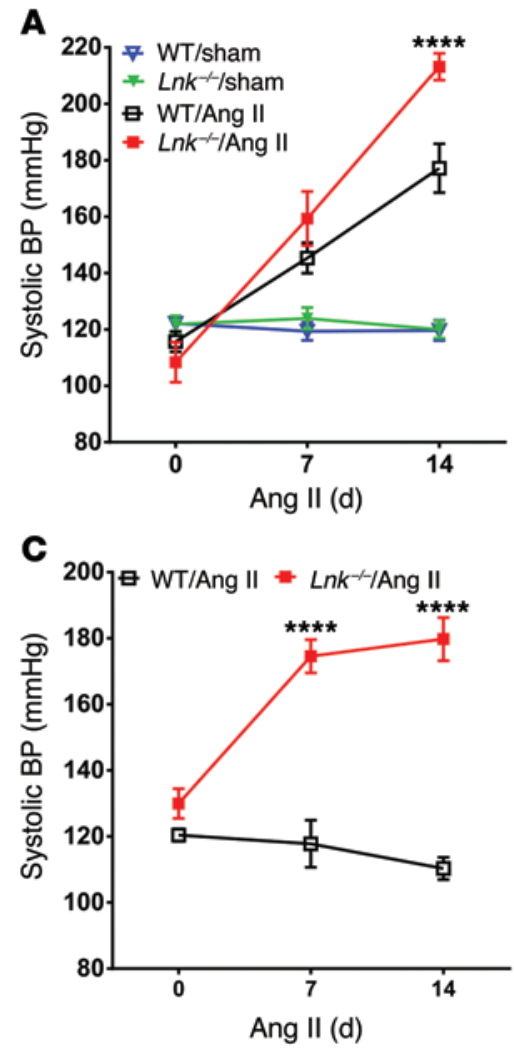
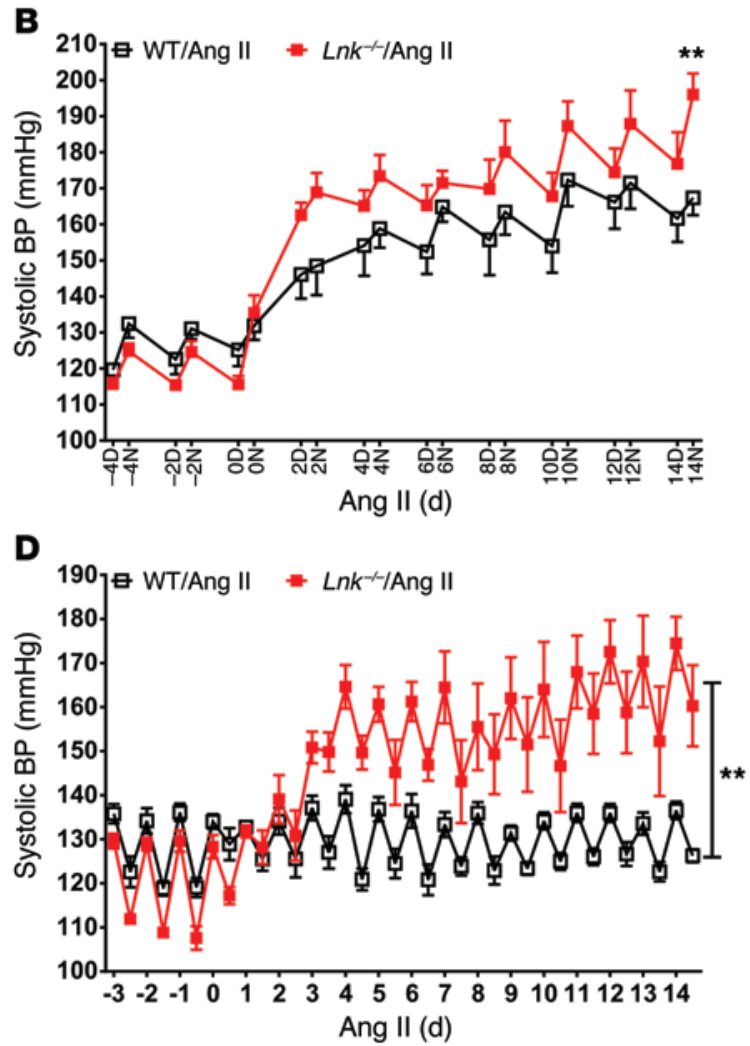

Figure 1. Loss of LNK exacerbates Ang II-induced hypertension. Mice received either $490 \mathrm{ng} / \mathrm{kg} / \mathrm{min}$ of Ang II (A and $\mathbf{B}$ ) or a normally subpressor dose of $140 \mathrm{ng} / \mathrm{kg} / \mathrm{min}$ of Ang II (C and D). BP was measured noninvasively via tail cuff (A and $\mathbf{C}$ ) or by telemetry (B and D). Data are expressed as mean \pm SEM. $n=3-4$ per group (A); $n=6-7$ per group (B); $n=5$ per group (C and D). Data were analyzed by ANOVA with repeated measures, 2-way ANOVA, or Student's $t$ test at specific time points. ${ }^{* *} P<0.01 ;{ }^{* * *} P<0.0001$ vs. WT/Ang II.

\section{Results}

Deficiency of LNK exacerbates Ang II-induced hypertension. To determine whether LNK is involved in BP regulation, we measured BP in $\mathrm{Lnk}^{-/-}$mice and C57BL/6J WT controls using both the noninvasive tail-cuff method and invasive monitoring with radiotelemetry in freely moving mice. BPs in vehicle-infused (sham) mice were similar between $\mathrm{Lnk}^{-/}$mice and WT controls, indicating that loss of LNK does not affect baseline BP (Figure 1A). However, infusion of a pressor dose of Ang II (490 $\mathrm{ng} / \mathrm{kg} / \mathrm{min}$ ) for 14 days resulted in a $35-\mathrm{mmHg}$ increase in $\mathrm{BP}$ in $\mathrm{Lnk}^{-/}$mice compared with WT controls (Figure 1A). The degree of hypertension in the $\mathrm{Lnk}^{-/-}$mice was profound (>200 $\mathrm{mmHg}$ ). Telemetry (Figure 1B) confirmed a $30-\mathrm{mmHg}$ increase in systolic pressure in $\mathrm{Lnk}^{-/-}$mice compared with WT controls after 14 days of Ang II infusion, with values approaching $200 \mathrm{mmHg}$ in the $\mathrm{Lnk}^{-/}$mice. To further validate these findings and determine whether Lnk deficiency lowers the threshold for developing hypertension, we tested a subpressor dose of Ang II (140 ng/ $\mathrm{kg} / \mathrm{min}$ ) that we have previously shown does not raise BP in WT mice (12). Indeed, WT mice had no increase in BP, whereas $\mathrm{Lnk}^{-/-}$mice had a significant increase in systolic BP, to 160$180 \mathrm{mmHg}$, as measured by tail cuff (Figure 1C) and confirmed by telemetry (Figure 1D). Diastolic BP and mean arterial BP were similarly elevated in response to this subpressor dose of Ang II (Supplemental Figure 1, A and B). Heart rates were similar between WT and $\mathrm{Lnk}^{-/-}$mice (Supplemental Figure $1 \mathrm{C}$ ). Interestingly, $\mathrm{Lnk}^{-/-}$mice displayed reduced activity compared with WT mice at baseline and during Ang II infusion (Supplemental Figure 1D).

Lnk $^{-/}$mice exhibit enhanced renal T cell and monocyte/macrophage infiltration. Renal dysfunction is both a cause and consequence of elevated BP. We therefore hypothesized that $\mathrm{Lnk}^{-/-}$mice would exhibit increased renal inflammation and dysfunction. To test this hypothesis, we first employed immunohistochemistry for CD3 (pan $\mathrm{T}$ cell marker) and F4/80 (monocyte/macrophage marker) in renal cortical and medullary sections from WT and $L n k^{-/-}$mice following 2 weeks of vehicle (sham) or $490 \mathrm{ng} / \mathrm{kg} / \mathrm{min}$ Ang II infusion. Interestingly, although baseline BP was not changed in $\mathrm{Lnk}^{-/}$mice, vehicleinfused $\mathrm{Lnk}^{--}$mice had more T cells in the renal cortex and medulla (Figure 2A) and more monocytes/macrophages around cortical glomeruli (Figure 2B) compared with WT mice. Of note, there were virtually no $\mathrm{F} 4 / 80^{+}$cells seen in the renal medulla of any of the mice. $\mathrm{T}$ cell and monocyte/macrophage infiltration were further increased in the $\mathrm{Lnk}^{-/-}$mice exposed to 2 weeks of Ang II (Figure 2).

To further characterize the renal inflammation, we made single-cell suspensions from kidneys of WT and $\mathrm{Lnk}^{-/-}$mice and performed flow cytometry to detect total leukocytes (CD45 ${ }^{+}$cells), total $\mathrm{T}$ lymphocytes $\left(\mathrm{CD} 45^{+} \mathrm{CD}^{+}\right.$cells), $\mathrm{T}$ cell subsets $\left(\mathrm{CD} 4^{+}\right.$, $\mathrm{CD}^{+}$, and $\mathrm{CD}^{+} \mathrm{CD}^{-} \mathrm{CD}^{-}$cells), and monocytes/macrophages $\left(\mathrm{CD} 45^{+} \mathrm{F} 4 / 80^{+}\right.$cells). Representative flow cytometry images are shown in Figure 3A. Ang II infusion increased total renal leukocytes, $\mathrm{T}$ cells, and monocytes/macrophages in WT mice (Figure $3, \mathrm{~B}-\mathrm{G}$ ). $\mathrm{Lnk}^{-1-}$ mice had increased infiltration of total leukocytes, T cells, and monocytes/macrophages at baseline (vehicle infusion) and in response to Ang II (490 ng/ kg/min) compared with WT mice (Figure $3, \mathrm{~B}-\mathrm{G})$. We also examined renal inflammation in response to the normally subpressor dose of Ang II (140 ng/ kg/min). In response to this lower dose of Ang II, $\mathrm{Lnk}^{-/-}$mice had increased renal inflammation compared with WT mice (Supplemental Figure 2, A-F).

Lnk deficiency promotes renal oxidative stress and glomerular injury. Increased ROS in the kidney has been reported in multiple models of hypertension. Superoxide has been identified as 
A
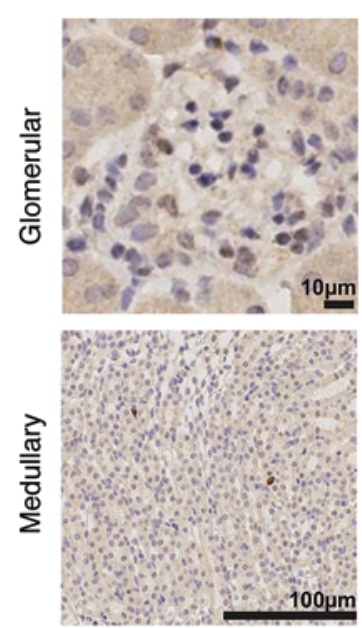

B
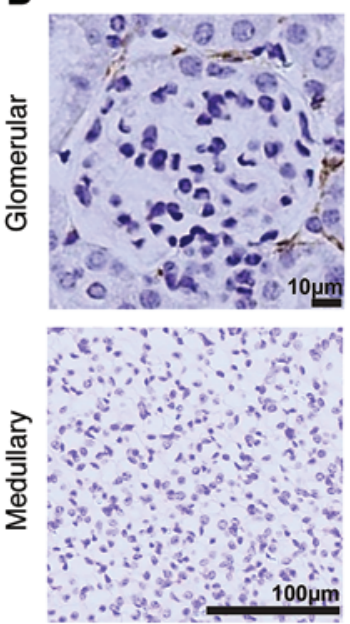

WT/Ang II
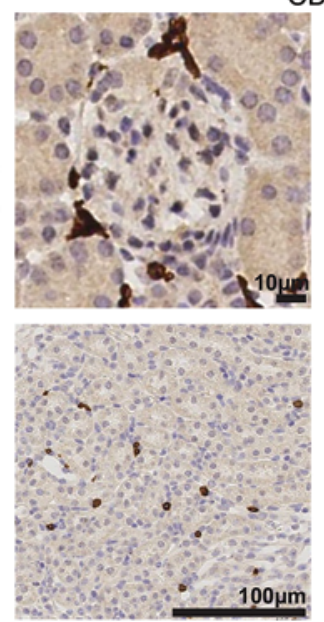

Lnk $k^{-1 /}$ sham
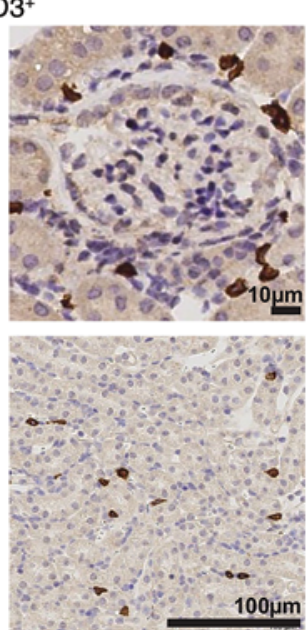

$\mathrm{F} 4 / 80^{+}$
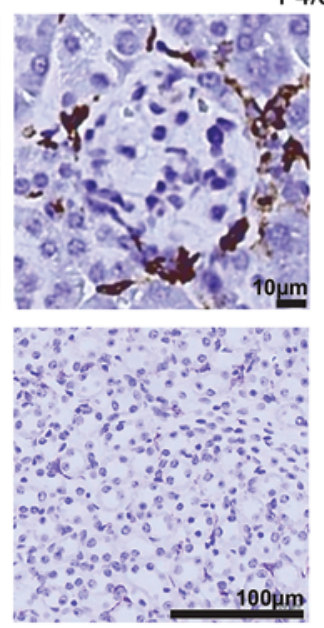
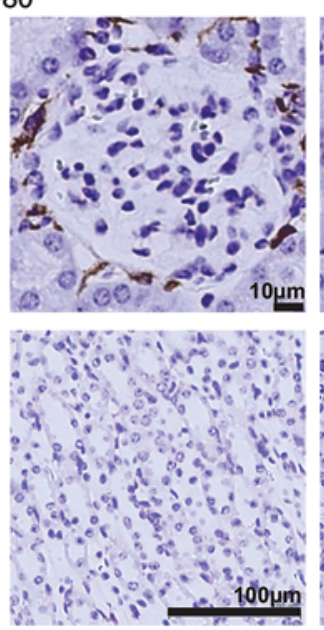

Lnk ${ }^{-1 /}$ Ang II
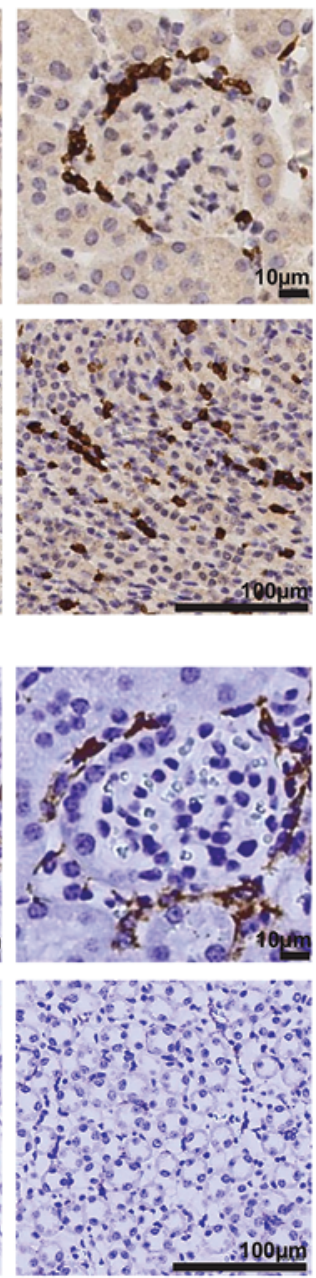

Figure 2. Immunohistochemistry for T lymphocytes and monocytes/macrophages in glomerular and medullary regions of the kidney. Representative immunohistochemistry images for the T cell marker CD3 (A) and monocyte/macrophage marker F4/80 (B) around cortical glomeruli and in the medulla of WT and $\mathrm{Lnk}^{-1-}$ mice infused with vehicle (sham) or Ang II (490 $\mathrm{ng} / \mathrm{kg} / \mathrm{min}$ ) for 2 weeks ( $n=4-8$ per group).

the principal ROS implicated in vascular and tubular dysfunction (13). We therefore measured superoxide levels by dihydroethidium (DHE)/HPLC analysis in WT and $\mathrm{Lnk}^{-/-}$mice exposed to vehicle (sham) or Ang II (490 $\mathrm{ng} / \mathrm{kg} / \mathrm{min})$ infusion. Ang II increased superoxide levels in the renal cortex, with a trend toward increased superoxide levels in the renal medulla (Figure $4, \mathrm{~A}$ and B). Loss of LNK enhanced superoxide levels in the cortex and medulla, with $\mathrm{Lnk}^{-/-}$mice exposed to vehicle having levels of superoxide similar to those of WT mice exposed to 2 weeks of Ang II. We performed DHE staining of frozen kidney sections to determine the cell types involved in ROS generation. As shown in Figure 4C, the source of ROS in the kidney is fairly ubiquitous, but mostly generated from vascular endothelial and renal tubular cells. Of note, there was very little DHE staining in and around glomeruli (not shown) despite the presence of inflammatory cells in this region. We then investigated glomerular and tubular injury in WT and $\mathrm{Lnk}^{-1-}$ mice. Albuminuria and nephrinuria were used as markers of glomerular injury. $\mathrm{Lnk}^{-/-}$mice had elevated levels of albuminuria and nephrinuria compared with WT mice following vehicle infusion (sham) and exhibited a marked increase to $300 \mu \mathrm{g} / \mathrm{d}$ of albuminuria and $20 \mu \mathrm{g} / \mathrm{d}$ of nephrinuria with Ang II infusion (Figure 4, D and E). Neutrophil gelatinase-associated lipocalin $(N G A L)$ mRNA levels, reflect- ing renal tubular damage, were measured by real-time quantitative reverse-transcription PCR (qRT-PCR) in whole kidneys, and NGAL protein was quantified in 24-hour urine samples by ELISA. While Ang II infusion increased NGAL mRNA and urine NGAL, loss of LNK had little or no effect on NGAL levels (Figure 4, F and G). We also examined excretion of albumin and NGAL in WT and $\mathrm{Lnk}^{-/-}$mice exposed to the normally subpressor dose of Ang II. Again, loss of LNK resulted in increased albuminuria but no change in urinary NGAL levels (Supplemental Figure 2, $\mathrm{G}$ and $\mathrm{H}$ ). Taken together, these data indicate that loss of LNK primarily exacerbates glomerular injury.

To determine the effect of this enhanced inflammation, oxidative stress, and glomerular injury on renal function, a sodium challenge study was performed as described in Trott et al. (14). Although there was no effect on baseline BPs in $\mathrm{Lnk}^{-/-}$mice, we hypothesized that their predisposition to hypertension was due to a shift in the pressure-natriuresis curve. We assessed this by injecting mice intraperitoneally with a saline load equal to $10 \%$ of their body weight. The mice were then placed in a metabolic chamber for the ensuing 4 hours, and urine volume and sodium content were measured. WT mice excreted $100 \%$ or more of the exogenous load, whereas $\mathrm{Lnk}^{-/-}$mice retained $40 \%$ of the injected volume and excreted half as much sodium (Figure 4, H and I). 

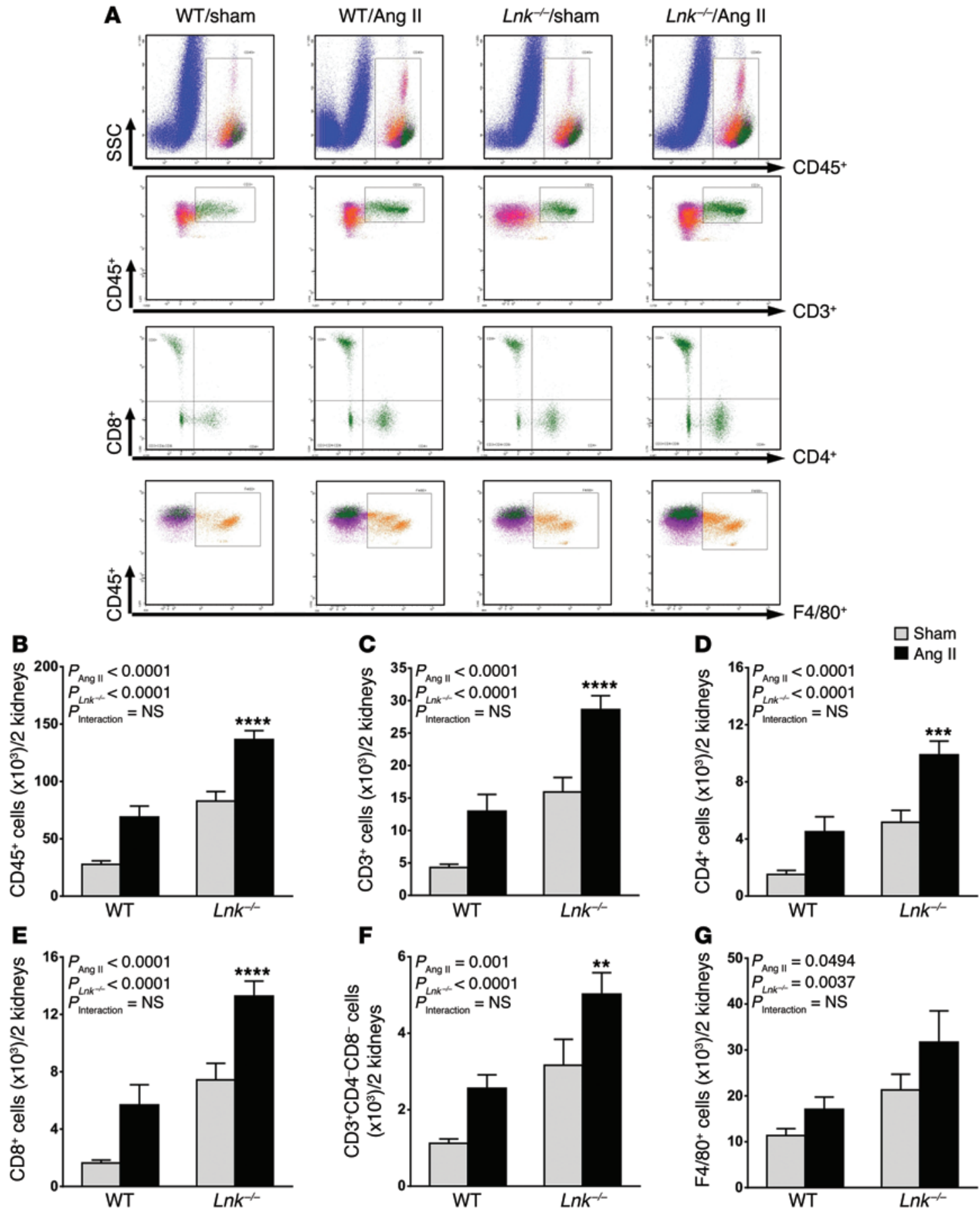

Figure 3. Lnk deficiency results in increased renal inflammation. (A) Representative flow cytometry dot plots showing gating strategy for renal-infiltrat-

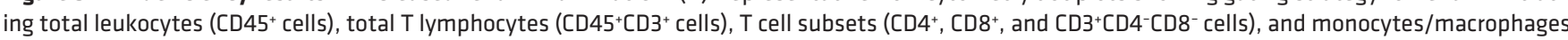
(CD45+F4/80+ cells). (B-C) Summary data of absolute numbers of indicated cell types per 2 kidneys in WT and $\mathrm{Lnk}^{-1-}$ mice infused with vehicle (sham) or Ang II (490 $\mathrm{ng} / \mathrm{kg} / \mathrm{min})$ for 2 weeks. Data are expressed as mean \pm SEM ( $n=10-11$ per group). $P$ values for the effect of Ang II, the effect of $L n k$ deficiency, and the interaction of Ang II and genotype as calculated by 2-way ANOVA are shown. ${ }^{* *} P<0.01 ;{ }^{* *} P<0.001 ;{ }^{* * *} P<0.0001$ vs. WT/Ang II.

Lnk $^{--}$mice exhibit enhanced vascular inflammation and dysfunction. We have previously shown that Ang II increases T cell infiltration into the perivascular fat and that this contributes to vascular dysfunction, a key feature of hypertension (6). We examined the effect of $L n k$ deficiency on vascular inflammation using flow cytometry on single-cell suspensions of aortic homogenates to detect total leukocytes $\left(\mathrm{CD} 45^{+}\right.$cells), total $\mathrm{T}$ lymphocytes
$\left(\mathrm{CD} 45^{+} \mathrm{CD}^{+}\right.$cells), $\mathrm{T}$ cell subsets $\left(\mathrm{CD} 4^{+}, \mathrm{CD} 8^{+}\right.$, and $\mathrm{CD}^{+} \mathrm{CD} 4^{-}$ CD8 ${ }^{-}$cells), and monocytes/macrophages $\left(\mathrm{CD} 45^{+} \mathrm{F} 4 / 80^{+}\right.$cells). Similar to our findings in the kidney, $\mathrm{Lnk}^{-/}$aortas had increased inflammation at baseline (vehicle infusion) compared with WT mice and this was markedly enhanced by Ang II infusion (490 ng/ $\mathrm{kg} / \mathrm{min}$ ). In fact, Ang II infusion resulted in approximately 3-fold more total leukocytes and $\mathrm{T}$ cells in $\mathrm{Lnk}^{-1-}$ vessels compared with 
A
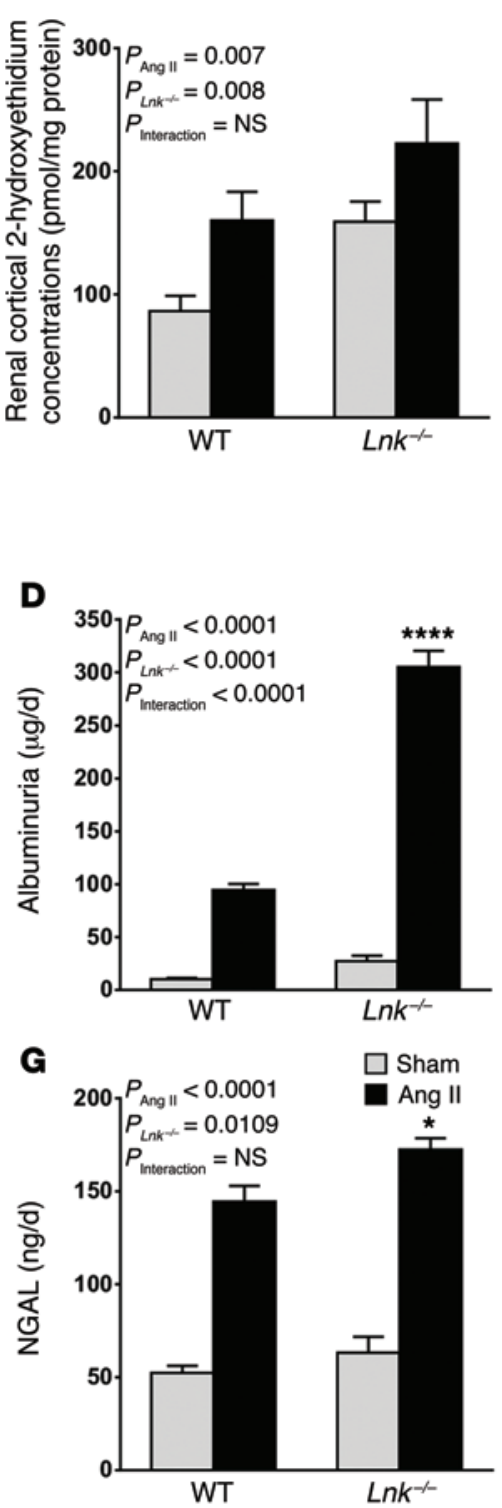

B

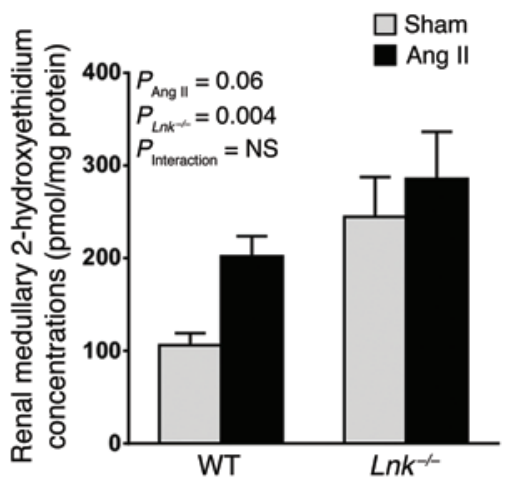

C
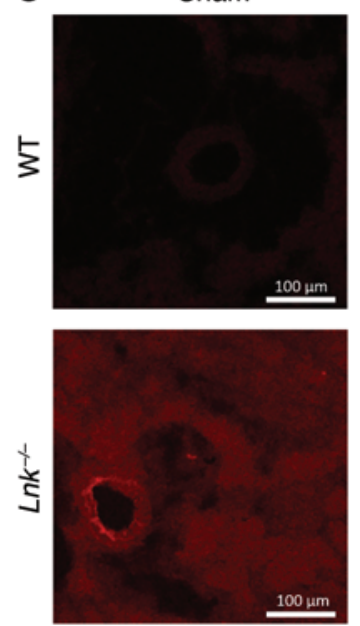

$\mathbf{F}$

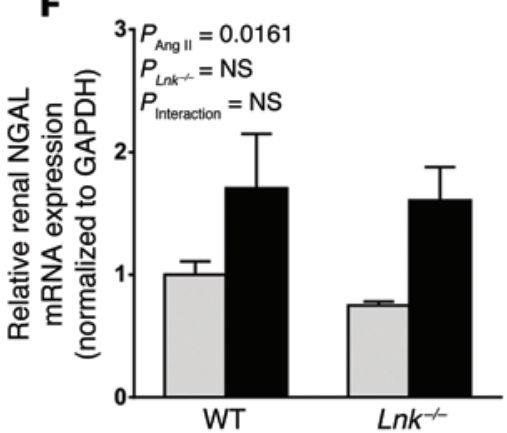

I

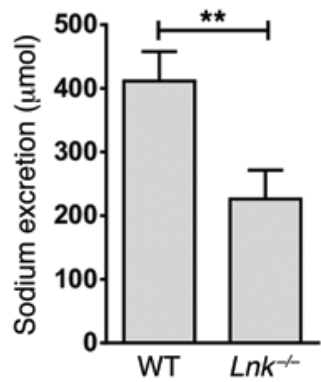

Figure 4. Loss of LNK promotes renal oxidative stress and glomerular injury. WT and $L n k^{-1-}$ mice were infused with vehicle (sham) or Ang II (490 ng/ $\mathrm{kg} / \mathrm{min}$ ) for 2 weeks. Quantitative analysis of superoxide levels, as detected by 2 -hydroxyethidium, in renal cortex (A) and medulla (B). $n=9$ per group. (C) Representative micrographs of DHE staining in kidney ( $n=3$ per group). Glomerular filtration barrier injury was assessed by quantifying 24-hour urinary excretion of albumin (D) and nephrin (E). $n=6$ per group. Renal tubular damage was evaluated by measuring total kidney mRNA NGAL expression (F) ( $n=4-5$ per group) and 24-hour urinary NGAL excretion (C) ( $n=7$ per group). Renal function was assessed by injecting mice intraperitoneally with a saline load equal to $10 \%$ body weight and determining urine volume $(\mathbf{H})$ and sodium excretion (I) over the ensuing 4 hours using a metabolic chamber ( $n=7-8$ per group). Data are expressed as mean \pm SEM. $P$ values for the effect of Ang II, the effect of $L n k$ deficiency, and the interaction of Ang II and genotype as calculated by 2-way ANOVA are shown for A, B, and D-G. ${ }^{*} P<0.05$; ${ }^{* * * *} P<0.0001$ vs. WT/Ang II. For H and I, unpaired Student's 1 -tailed $t$ test was used. ${ }^{* *} P<0.01$ vs. WT.

WT vessels (Figure $5, \mathrm{~A}-\mathrm{F}$ ). In response to the normally subpressor dose of Ang II (140 ng/ kg/min), loss of LNK was also associated with increased total leukocyte, $\mathrm{T}$ cell, and monocyte/macrophage infiltration (Supplemental Figure 2, I-N).

We then examined vascular function by measuring endothelium-dependent and -independent relaxation of thoracic aortic rings from WT and $L n k^{-/-}$mice. As previously reported, Ang II (490 ng/ $\mathrm{kg} / \mathrm{min}$ ) was associated with blunted endothelium-dependent relax- ation to acetylcholine in WT mice (7). $\mathrm{Lnk}^{-/-}$mice exhibited greater impairment of endothelial-dependent relaxation in response to Ang II compared with WT mice (Figure 5G). Ang II also impaired endothelium-independent relaxation to nitroglycerin, but loss of LNK had no further effect on relaxation to nitroglycerin (Figure $5 \mathrm{H}$ ).

Endothelial nitric oxide (NO) synthase is an important downstream target of LNK in endothelial cells (5). Since aortic NO levels correlate with endothelium-dependent relaxation, we 
A

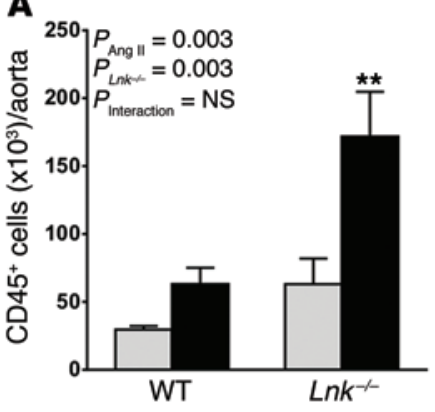

D

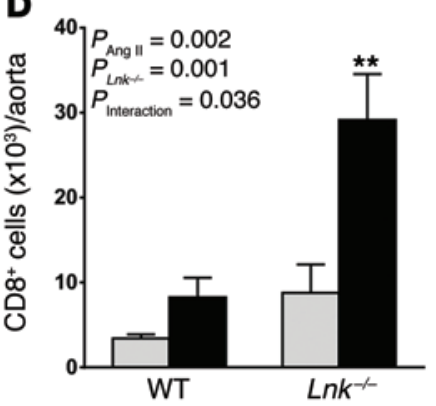

G

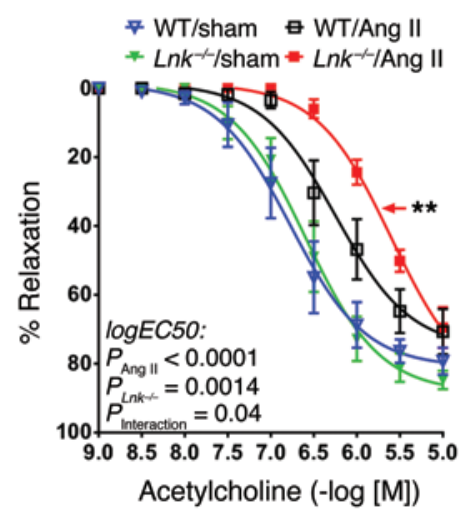

B

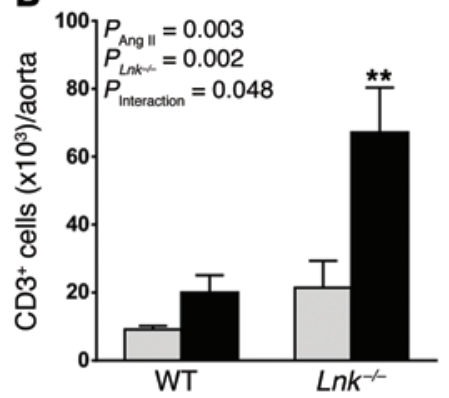

E

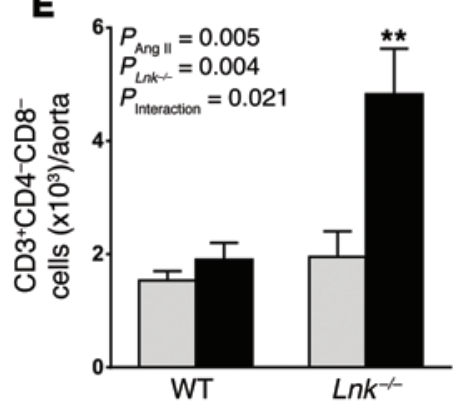

H

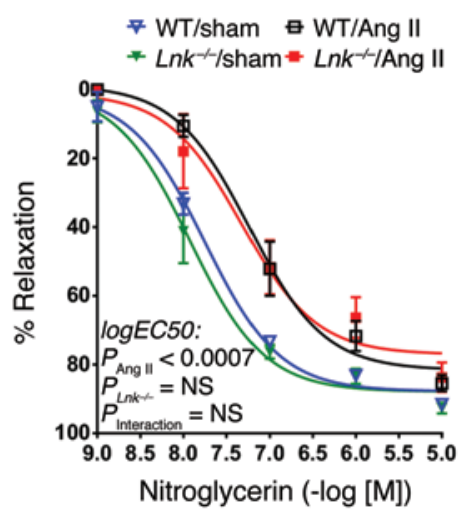

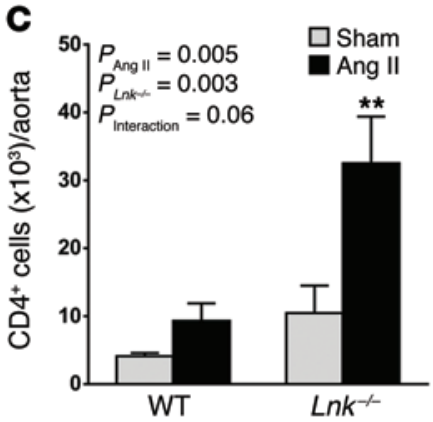

$\mathbf{F}$

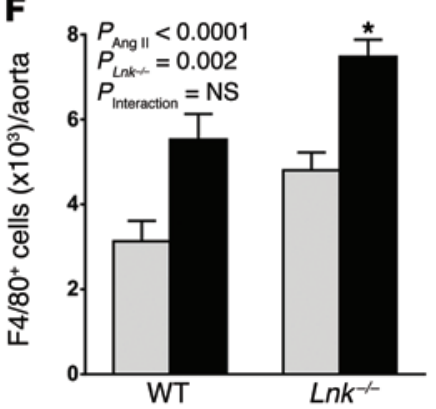

I
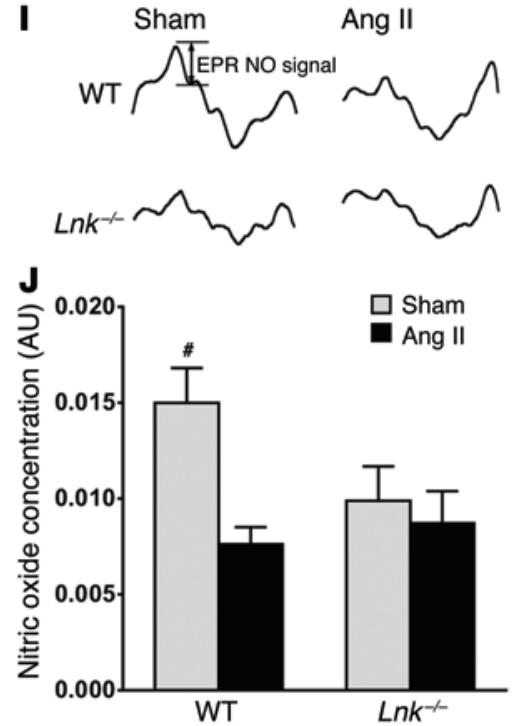

Figure 5. Lnk deficiency exacerbates vascular inflammation and dysfunction. (A-F) Quantification of flow cytometry for total leukocytes (CD45+ cells), total T lymphocytes (CD45 ${ }^{+} \mathrm{CD3}^{+}$cells), $\mathrm{T}$ cell subsets ( $\mathrm{CD} 4^{+}, \mathrm{CD} 8^{+}$, and $\mathrm{CD3^{+ }} \mathrm{CD}^{-} \mathrm{CD} 8^{-}$cells), and monocytes/macrophages (CD45 ${ }^{+} \mathrm{F} 4 / 80^{+}$cells) in thoracic aortas of WT and $L n k^{-1-}$ mice infused with vehicle (sham) or Ang II (490 ng/kg/min) for 2 weeks ( $n=5$ per group). Endothelium-dependent relaxation to acetylcholine $\mathbf{( G )}$ and endothelium-independent relaxation to nitroglycerin $(\mathbf{H})$ of thoracic aortic segments $(n=5-6$ per group). Aortic NO levels were measured from thoracic aortic segments using EPR. (I) Example of EPR spectra from the indicated groups. (J) Summary data of aortic NO levels ( $n=7-9$ per group). Data are expressed as mean \pm SEM. $P$ values for the effect of Ang II, the effect of $L n k$ deficiency, and the interaction of Ang II and genotype as calculated by 2 -way ANOVA are shown for $\mathbf{A}-\mathbf{H}$. ${ }^{*} P<0.05 ;{ }^{*} P<0.01$ vs. WT/Ang II; ${ }^{*} P<0.05$ compared with the other 3 groups.

hypothesized that $L n k^{-/}$aortas would have decreased NO levels. We measured NO from thoracic aortic rings of WT and Lnk $^{-1-}$ mice using electron paramagnetic resonance (EPR). As expected, Ang II decreased NO levels in WT vessels by approximately 2-fold. Interestingly, $\mathrm{LnK}^{-/-}$vessels exhibited reduced levels of $\mathrm{NO}$ at baseline (sham). Ang II infusion into $\mathrm{Lnk}^{-/}$mice did not further reduce vascular NO, but this could be due to technical limitations of the assay, since the NO signal was already at the lower limits of detection in $\mathrm{Lnk}^{-/-}$mice at baseline (Figure 5, I and J). Taken together, these data demonstrate that $\mathrm{Lnk}^{-/-}$vessels exhibit enhanced inflammatory cell infiltration, decreased NO levels, and impaired endothelium-dependent relaxation compared with WT vessels.

Lnk deficiency in hematopoietic cells is primarily responsible for the aggravated hypertensive response. LNK is expressed in hematopoietic cells, endothelial cells, and other stromal tissues, such as the testis, brain, and muscle. Therefore, to examine the source of LNK that is relevant to hypertension, we performed BMT experiments. BM $\left(20 \times 10^{6}\right.$ cells $)$ from SJL (CD45.1) donor mice was transplanted into irradiated $\mathrm{Lnk}^{-/}$(CD45.2) mice and cells from 
A

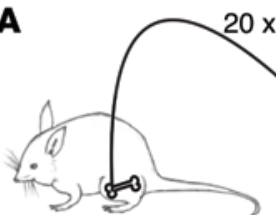

WT

SJL (CD45.1) $20 \times 10^{6}$ cells

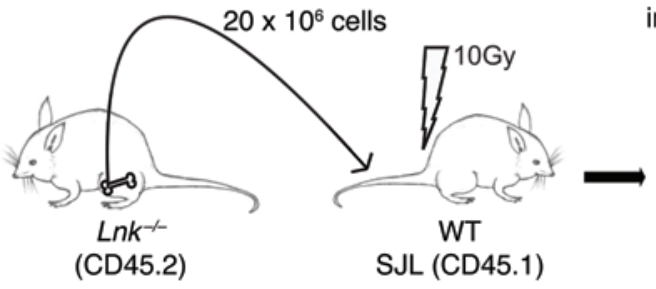

Lnk $1-$

(CD45.2)

SJL (CD45.1)

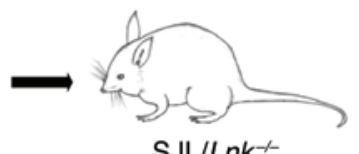

SJL/Lnk ${ }^{-1}$

LNK deficiency is only

in endothelial cells and other

nonhematopoietic cells

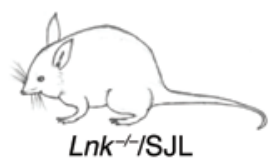

LNK deficiency is only in hematopoietic cells

$\mathbf{B}$
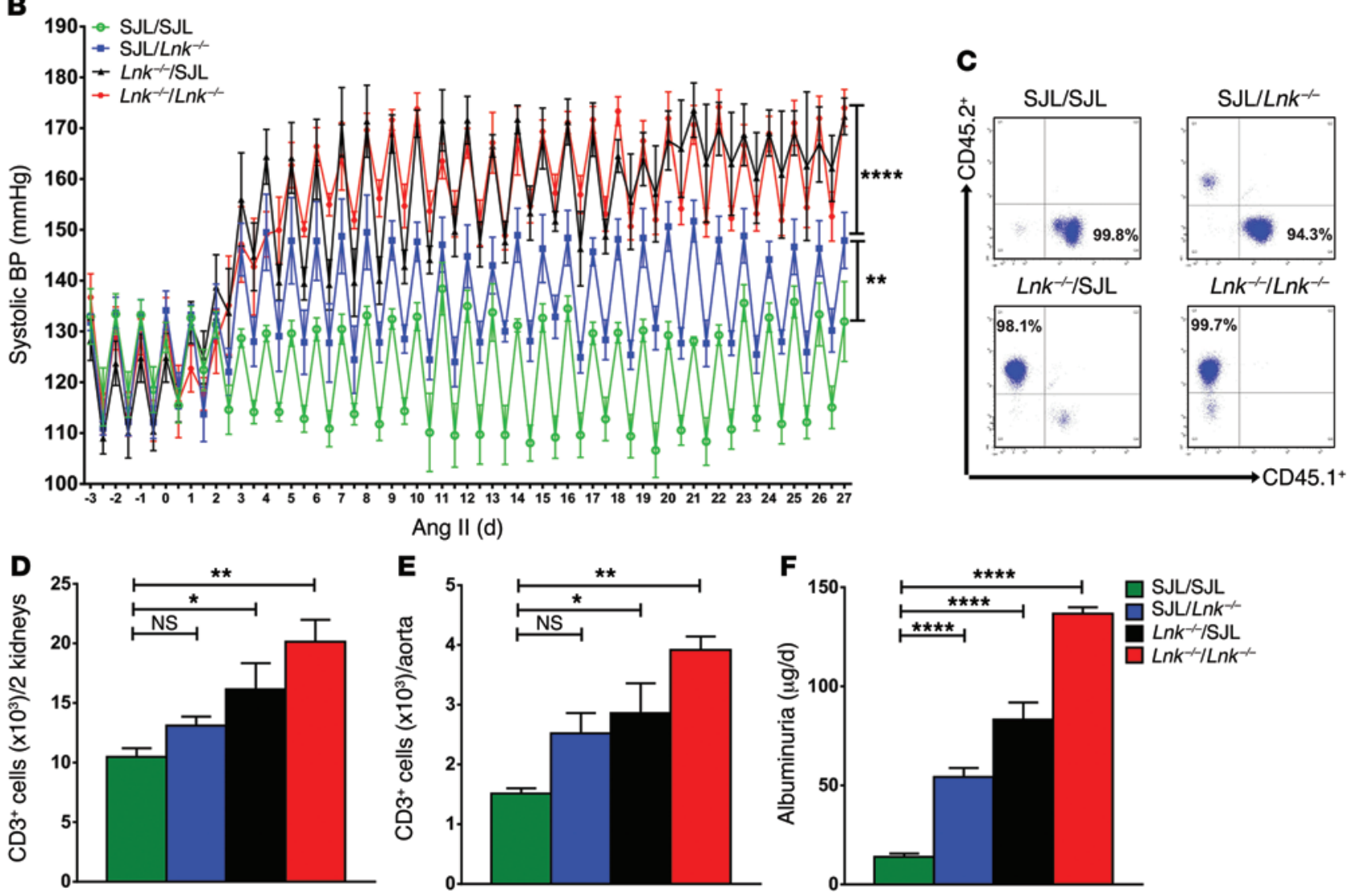

Figure 6. BMT studies to determine the relative role of hematopoietic versus somatic LNK in the aggravated hypertensive response to Ang II. (A) Experimental design: BMT was performed using Lnk $^{-1-}$ (CD45.2) and WT SJL (CD45.1) mice as either donors or recipients as indicated. Four groups were des-

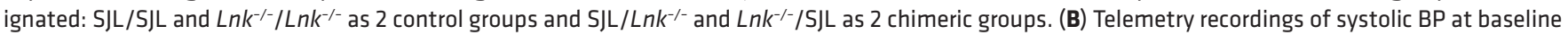
and during 28 days of a normally subpressor infusion of Ang II (140 ng/ $\mathrm{kg} / \mathrm{min})$. (C) Percentage of chimerism was assessed by flow cytometry for CD45.1/ CD45.2 in peripheral blood mononuclear cells. A representative plot from each group is shown. In all cases, the amount of chimerism was $90 \%$ or more. Quantification of flow cytometry for total T lymphocytes (CD45+CD3+ cells) in kidneys (D) and thoracic aortas (E) in the designated 4 groups. (F) 24-hour urinary excretion of albumin in the designated 4 groups. Data are expressed as mean \pm SEM ( $n=5$ per group except for panel $\mathbf{E}$, in which $n=3$ per group). For B, repeated measures ANOVA was performed. ${ }^{* *} P<0.01 \mathrm{vs}$. SJL/SJL; ${ }^{* * *} P<0.0001 \mathrm{vs}$. SJL/Lnk ${ }^{-1}$. For $\mathbf{D}-\mathbf{F}, 1$-way ANOVA was performed. ${ }^{*} P<0.05$; ${ }^{* *} P<0.01 ;{ }^{* * *} P<0.0001$ vs. SJL/SJL.

irradiated $\mathrm{Lnk}^{-1-}$ mice were transplanted into donor mice to create chimeric mice in which Lnk deficiency was present in stromal

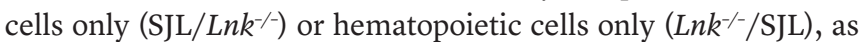
shown in Figure 6A. Irradiated SJL mice transplanted with SJL marrow (SJL/SJL) and irradiated $\mathrm{Lnk}^{-/}$mice transplanted with
Lnk $k^{-1-}$ marrow $\left(\operatorname{Lnk}^{-1-} / \operatorname{Lnk}^{-1-}\right)$ served as controls. After an 8-week engraftment period, radiotelemeters were implanted and baseline BPs were obtained. Then a normally subpressor dose of Ang II (140 ng/ $/ \mathrm{kg} / \mathrm{min})$ was infused via an osmotic minipump into all mice for 4 weeks. Day and night BPs were recorded via telemetry 

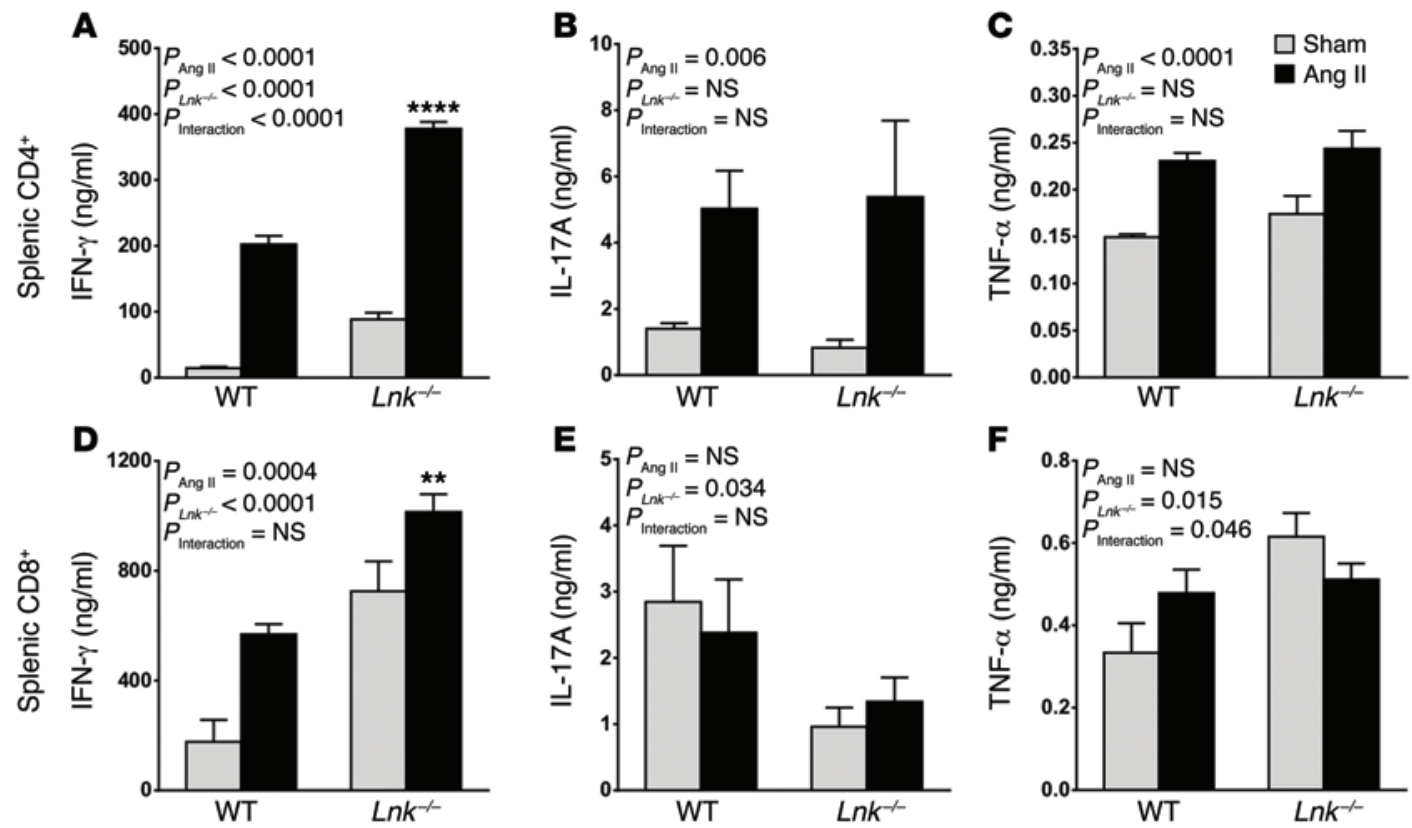

G
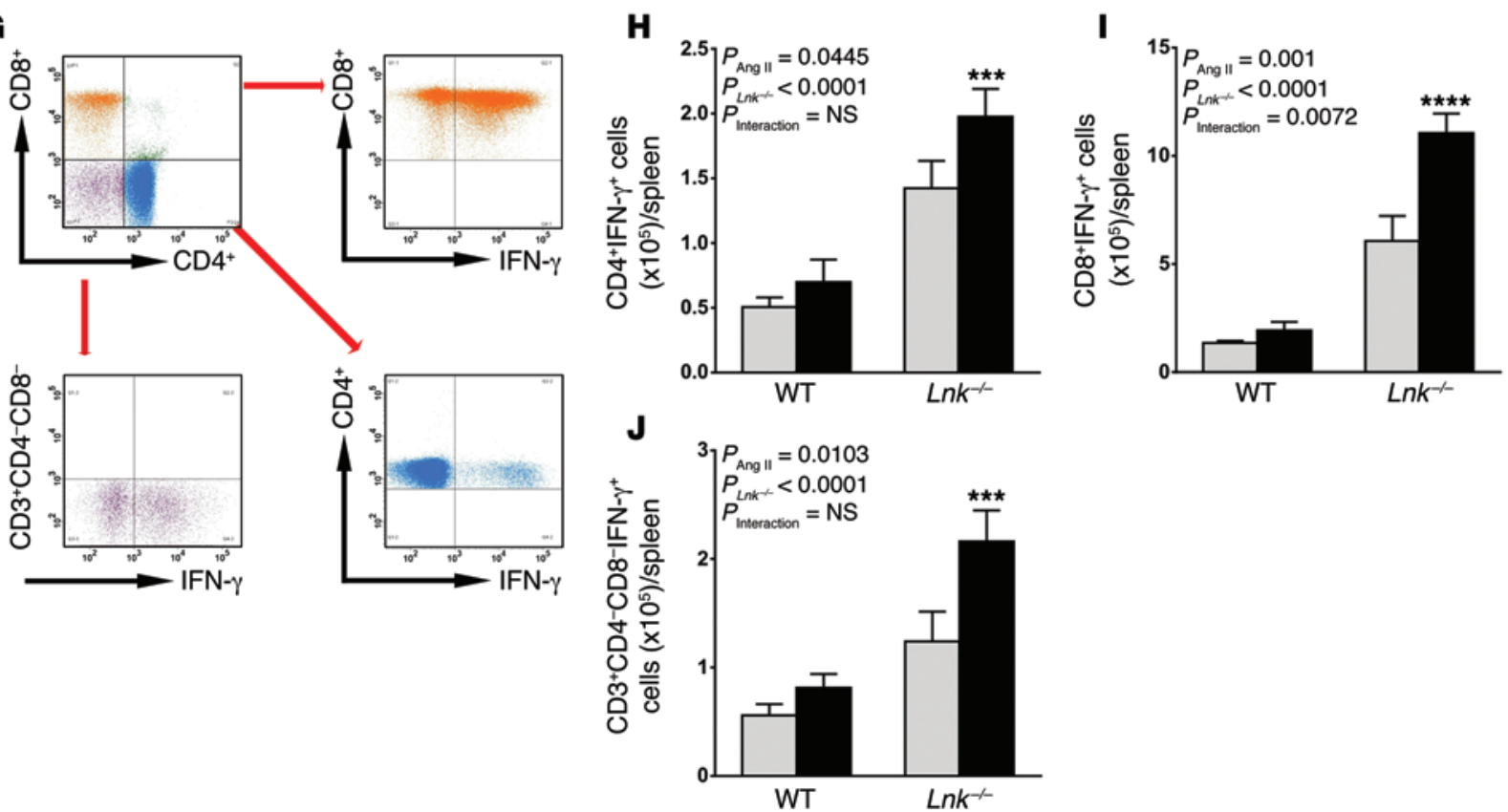

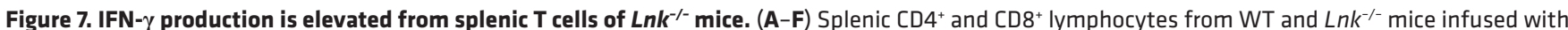
vehicle (sham) or Ang II (490 ng/kg/min) for 2 weeks were cultured on anti-CD3 plates in the presence of anti-CD28 antibodies for 48 hours. Culture supernatants were analyzed for IFN- $\gamma$, IL-17A, or TNF- $\alpha$ using a Luminex-based assay ( $n=5$ per group). (G) Representative flow cytometry dot plots showing gating strategy to identify total number of $\mathrm{CD}^{+}, \mathrm{CD}^{+}$, and $\mathrm{CD} 3^{+} \mathrm{CD4} 4^{-} \mathrm{CD} 8^{-}$(double negative) T cells producing IFN- $\gamma$ by intracellular staining. Summary data ( $n=8$ per group) are shown in $\mathbf{H}-\mathrm{J}$. Data are expressed as mean \pm SEM. $P$ values for the effect of Ang II, the effect of $L n k$ deficiency, and the interaction of Ang II and genotype as calculated by 2-way ANOVA are shown. ${ }^{* *} P<0.01 ;{ }^{* *} P<0.001 ;{ }^{* * *} P<0.0001 \mathrm{vs}$. WT/Ang II.

for the entire Ang II-infusion period (Figure 6B). Importantly, loss of LNK in hematopoietic cells only ( $\left.\mathrm{Lnk}^{-/} / \mathrm{SJL}\right)$ completely reproduced the BP phenotype of the whole-body deletion of LNK, with BPs reaching 160 to $170 \mathrm{mmHg}$, as seen in the $\mathrm{Lnk}^{-/}$mice that received $\mathrm{Lnk}^{-1-}$ marrow (Figure 6B). Deficiency of LNK in somatic cells resulted in an intermediate hypertensive response, suggesting that there is some contribution of somatic LNK to BP regulation (Figure 6B). At the end of the study, the mice were sacrificed and peripheral blood mononuclear cells were analyzed for percentage of chimerism of CD45.1 and CD45.2. Representative flow cytometry images are shown in Figure 6C. In all cases, the amount of chimerism was greater than $90 \%$, indicating successful $\mathrm{BM}$ replacement by this protocol.

We also assessed renal and vascular inflammation by performing flow cytometry for total $\mathrm{T}$ cells $\left(\mathrm{CD} 45^{+} \mathrm{CD}^{+}\right.$cells $)$on kidneys and thoracic aortas of these mice after sacrifice. When compared with the SJL/SJL control group, loss of LNK only in somatic cells had no significant effect on renal or vascular $\mathrm{T}$ cell 

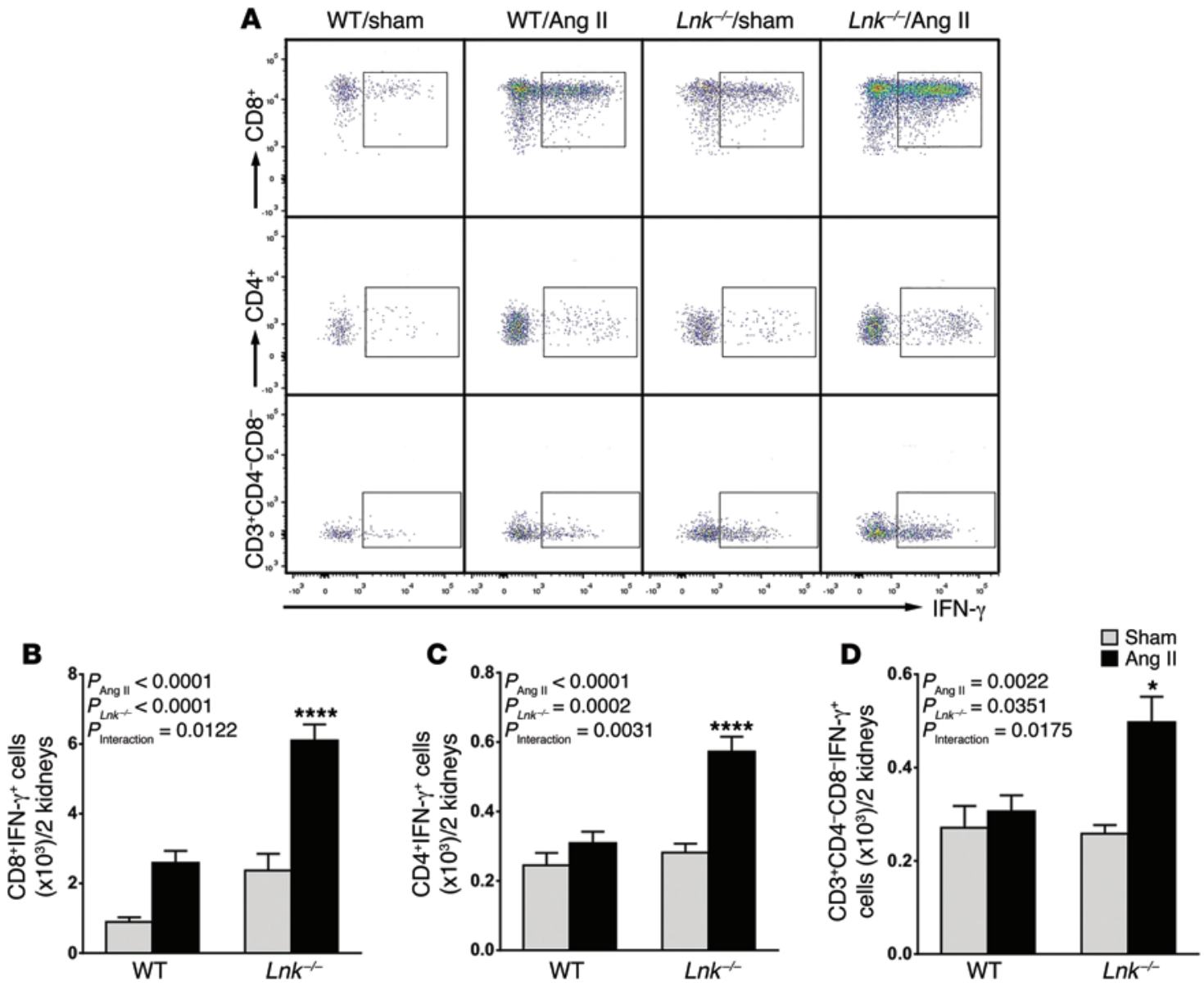

Figure 8. IFN- $\gamma$-producing T cells accumulate in kidneys of $\mathbf{L n k}^{-/-}$mice following Ang II infusion. Intracellular staining for IFN- $\gamma$ was performed on renalinfiltrating leukocytes from WT and $L \mathrm{n}^{-1-}$ mice infused with vehicle (sham) or Ang II ( $490 \mathrm{ng} / \mathrm{kg} / \mathrm{min}$ ) for 2 weeks. (A) Representative flow cytometry dot plots showing gating strategy to identify the total number of $\mathrm{CD}^{+}, \mathrm{CD}^{+}$, and $\mathrm{CD}^{+} \mathrm{CD} 4^{-} \mathrm{CD}^{-}$(double negative) $\mathrm{T}$ cells producing IFN- $\gamma$ by intracellular staining. Summary data ( $n=6-7$ per group) are shown in B-D. Data are expressed as mean \pm SEM. $P$ values for the effect of Ang II, the effect of $L n k$ deficiency, and the interaction of Ang II and genotype as calculated by 2 -way ANOVA are shown. ${ }^{*} P<0.05$; ${ }^{* * * *} P<0.0001 \mathrm{vs}$. WT/Ang II.

infiltration, but loss of LNK in hematopoietic cells significantly increased $\mathrm{T}$ cell infiltration into these organs (Figure 6, D and $\mathrm{E}$ ). Glomerular injury was assessed by collecting urine for 24 hours prior to sacrifice and measuring albumin in the urine by ELISA. As shown in Figure 6F, both chimeric groups had intermediate levels of albuminuria compared with the SJL/SJL control group. Loss of LNK in both hematopoietic and somatic cells resulted in the greatest degree of albuminuria. Thus, loss of LNK in hematopoietic cells is primarily responsible for renal/vascular inflammation and hypertension, but both hematopoietic and somatic LNK contribute to glomerular injury.

$T$ cells from $\mathrm{Lnk}^{-1-}$ mice produce elevated levels of IFN- $\gamma$, and IFN- $\gamma$-producing T cells, particularly $C D 8^{+} T$ cells, are increased in the spleen of $\mathrm{Lnk}^{-/-}$mice. Our BM transplantation studies indicate that the predominant effect of Lnk deficiency on inflammation and BP regulation is mediated by hematopoietic cells. Based on emerging evidence that $\mathrm{T}$ cells and $\mathrm{T}$ cell-derived cytokines are critical in hypertension $(6,7,11)$, we hypothesized that $L n k^{-/-} \mathrm{T}$ cells might display an altered profile of cytokine production either at baseline or in response to chronic Ang II infusion. To address this, we isolated splenic $\mathrm{CD}^{+}$and $\mathrm{CD}^{+} \mathrm{T}$ cells from WT and $\mathrm{Lnk^{-/ }}$ mice infused with vehicle (sham) or $490 \mathrm{ng} / \mathrm{kg} / \mathrm{min}$ Ang II for 2 weeks and cultured them on anti-CD3 plates in the presence of antiCD28 antibodies for 48 hours. The culture supernatant was then analyzed for IFN- $\gamma$, IL-17A, and TNF- $\alpha$ (Figure 7, A-F). In CD $4^{+} \mathrm{T}$ cells, Ang II increased production of all 3 cytokines, but Lnk deficiency only affected IFN- $\gamma$ production (Figure 7, A-C). $L n k^{-/-}$T cells produced more IFN- $\gamma$ at baseline, and this was further increased with Ang II infusion (Figure 7A). In $\mathrm{CD}^{+} \mathrm{T}$ cells, Ang II only increased IFN- $\gamma$ production, with no effect on IL-17A or TNF- $\alpha$ (Figure 7, D-F). Loss of LNK enhanced IFN- $\gamma$ production in $\mathrm{CD}^{+}$ $\mathrm{T}$ cells both at baseline and in response to Ang II infusion (Figure 7D). Lnk $^{-/} \mathrm{CD}^{+} \mathrm{T}$ cells appear to be skewed to a $\mathrm{T}_{\mathrm{C}} 1$ phenotype, with elevated production of IFN- $\gamma$ and TNF- $\alpha$ and decreased production of IL-17A (Figure 7, D-F).

Total leukocytes, $\mathrm{T}$ cells, $\mathrm{T}$ cell subsets, and IFN- $\gamma$-producing $\mathrm{T}$ cells were quantified in the spleen by flow cytometry. $\mathrm{Lnk}^{-/-}$ spleens were larger in size at baseline (Supplemental Figure 3A). Ang II infusion (490 ng/ $\mathrm{kg} / \mathrm{min}$ ) did not increase total leukocytes or T cells in WT mice. $\mathrm{Lnk}^{-/}$mice had 3- to 4-fold higher levels of total leukocytes and $\mathrm{T}$ cells in the spleen at baseline (vehicle infusion), with a slight increase in total leukocytes and most $\mathrm{T}$ cell subsets in response to Ang II infusion (Supplemental Figure 3, $\mathrm{B}-\mathrm{F})$. We then performed flow cytometry with intracellular stain- 
A

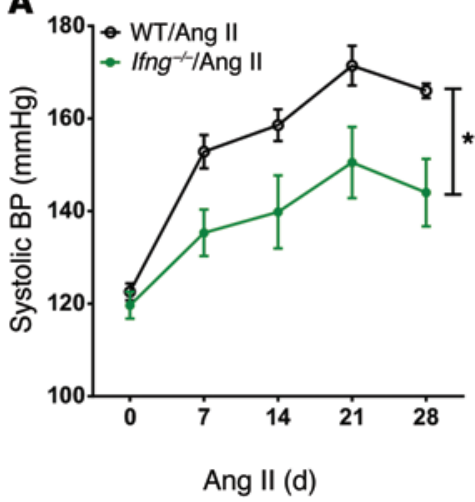

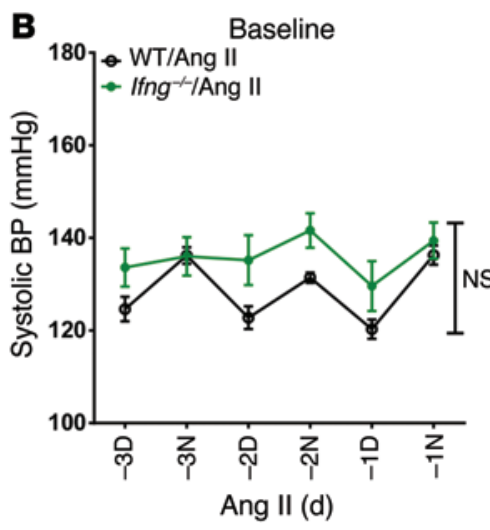

Figure 9. Ifng ${ }^{-/-}$mice develop blunted hypertension in response to Ang II. WT or Ifng ${ }^{-/-}$mice were infused with $490 \mathrm{ng} / \mathrm{kg} / \mathrm{min}$ of Ang II. BP was measured noninvasively via the tail-cuff method (A) ( $n=6-7$ per group) or by telemetry (B) ( $n=5-6$ per group). Telemetry recordings are shown for 3 days prior to Ang II infusion (baseline) and for days 13 to 15 of Ang II infusion. Data are expressed as mean \pm SEM. Data were analyzed by ANOVA with repeated measures. ${ }^{* *} P<0.01$ vs. WT/Ang II.

ing for IFN- $\gamma$ in spleens of WT and $\mathrm{Lnk}^{-/}$mice infused with vehicle (sham) or Ang II (490 ng/ $\mathrm{kg} / \mathrm{min}$ ) for 2 weeks. Representative flow cytometry dot plots showing gating for $\mathrm{T}$ cell subsets $\left(\mathrm{CD} 4^{+}\right.$, $\mathrm{CD}^{+}$, and $\mathrm{CD}^{+} \mathrm{CD} 4^{-} \mathrm{CD} 8^{-}$cells) and IFN- $\gamma$-producing cells within each subset are shown in Figure 7G. Within all $3 \mathrm{~T}$ cell subsets, Ang II and loss of LNK were associated with elevated numbers of IFN- $\gamma$-producing cells, with the highest numbers of IFN- $\gamma$-positive cells found within the $\mathrm{CD} 8^{+} \mathrm{T}$ cell subset of $\mathrm{Lnk}^{--}$mice infused with Ang II (Figure 7, H-J).

$C D 8^{+} I F N-\gamma$-producing $T$ cells $\left(T_{c} 1\right.$ cells) accumulate in the kidneys of $\mathrm{Lnk}^{-/-}$mice. To determine whether IFN- $\gamma$ production is increased in peripheral organs in addition to the spleen, we performed intracellular staining followed by flow cytometry in kidneys of WT and $\mathrm{Lnk}^{-/}$mice exposed to 2 weeks of vehicle (sham) or $490 \mathrm{ng} / \mathrm{kg} /$ min of Ang II. Representative flow cytometry dot plots showing total number of IFN- $\gamma$-producing cells within each $\mathrm{T}$ cell subset are shown in Figure 8A. Within the CD8 $8^{+} \mathrm{T}$ cell subset, loss of LNK is associated with elevated numbers of IFN- $\gamma$-producing cells, and this is further increased by Ang II (Figure 8B). Within the CD4 $4^{+}$ and double-negative $\mathrm{T}$ cell subsets, the numbers of IFN- $\gamma$-producing cells double in $\mathrm{Lnk}^{--}$mice exposed to Ang II (Figure 8, C and D), but it should be noted that most IFN- $\gamma$-producing cells in the kidney are $\mathrm{CD} 8^{+}$. In fact, IFN- $\gamma$-producing $\mathrm{CD}^{+} \mathrm{T}$ cells $\left(\mathrm{T}_{\mathrm{C}} 1\right.$ cells) were approximately 10 -fold higher in number than the other 2 subsets (Figure $8, \mathrm{~B}-\mathrm{D}$ ).

IFN- $\gamma$ promotes Ang II-dependent hypertension. The role of IFN- $\gamma$ in hypertension has not been well characterized. Because the most striking effect of $L n k$ deficiency on cytokine production is enhanced IFN- $\gamma$ production, particularly from $\mathrm{CD} 8^{+} \mathrm{T}$ cells, we investigated the effect of IFN- $\gamma$ on BP response to Ang II infusion $(490 \mathrm{ng} / \mathrm{kg} /$ min) using IFN- $\gamma$-deficient mice (Ifng ${ }^{-/}$). By both the noninvasive tail-cuff method and invasive radiotelemetry, If $\mathrm{fg}^{-/}$mice exhibited a 20-mmHg decrease in BP compared with WT mice in response to Ang II infusion (Figure 9). Thus, the effect of LNK on exacerbating hypertension and renal/vascular dysfunction is likely mediated, at least in part, by enhanced IFN- $\gamma$ production.

Loss of 1 LNK allele predisposes to hypertension and renal inflammation/injury. Common polymorphisms in humans are unlikely to result in complete loss of function. Thus, to simulate a less extreme deficiency of LNK, we also studied heterozygous mice, $\mathrm{Lnk}^{+/}$. When infused with the normally subpressor dose of Ang II (140 ng $/ \mathrm{kg} / \mathrm{min}$ ), $\mathrm{LnK}^{+/}$mice developed a modest increase in BP, to about $150 \mathrm{mmHg}$ (Supplemental Figure 4A). We then examined renal inflammation in these mice and found a modest increase in total leukocytes, $\mathrm{T}$ cells, and monocytes/macrophages, but not to the degree seen in homozygous Lnk-deficient mice (Supplemental Figure 2, A-F, and Supplemental Figure 4, B-G). Interestingly, albuminuria was similar between homozygous $\mathrm{Lnk}^{-/}$and heterozygous $L n k^{+/}$mice when infused with Ang II (Supplemental Figure $2 \mathrm{G}$ and Supplemental Figure $4 \mathrm{H}$ ). Thus, while there does appear to be a gene-dosage effect, these data demonstrate that loss of even 1 allele of LNK is sufficient to increase BP and result in renal inflammation/injury.

\section{Discussion}

In the present study, we report for what we believe is the first time that loss of the intracellular adaptor protein LNK contributes to hypertension and the associated inflammation and renal/vascular dysfunction. LNK serves as a "brake" to cellular proliferation and cytokine signaling in hematopoietic and endothelial cells. We found that loss of LNK leads to enhanced vascular and renal inflammation at baseline and that this is further exacerbated by Ang II infusion. BM transplantation studies showed that the predominant effect of LNK in BP regulation is through the hematopoietic compartment, further emphasizing the critical role of the immune system in hypertension. Furthermore, we show that $L n k$ deficiency results in increased IFN- $\gamma$ production, particularly from $\mathrm{CD} 8^{+} \mathrm{T}$ cells, and that IFN- $\gamma$ promotes Ang II-dependent hypertension.

There are emerging data that innate and adaptive immunity play a central role in hypertension. We and others have shown that Rag1 ${ }^{-/}$mice and rats, which lack both $\mathrm{T}$ and $\mathrm{B}$ lymphocytes, have blunted $\mathrm{BP}$ responses to various hypertensive stimuli and that this is reversed by adoptive transfer of $T$ lymphocytes $(6,15)$. The current study confirms this concept by showing that the enhanced $\mathrm{T}$ cell activation and infiltration in $\mathrm{Lnk}^{-/-}$mice exacerbate hypertension and its associated end-organ damage. Although $\mathrm{Lnk}^{-/-}$mice at baseline demonstrate increased renal and vascular inflammation, oxidative stress, and $\mathrm{T}$ cell cytokine production compared 
with WT mice, their baseline BPs are not elevated. At first glance, this seems contradictory to the premise that inflammation is a key contributor to hypertension. It should be stressed, however, that inflammation alone does not cause hypertension, but rather, it seems to enhance the response to various hypertensive stimuli. A "second hit, " such as Ang II or high salt, is necessary, and the underlying inflammatory substrate then exacerbates the response to the hypertensive stimulus and contributes to the end-organ damage associated with hypertension. Thus, the inflammatory milieu lowers the threshold or set point for developing hypertension in response to a hypertensive stimulus. This is clearly demonstrated in Figure 1, C and D, and Supplemental Figure 1, which shows that a subpressor dose of Ang II (140 ng/ kg/min) did not raise BP in WT mice, but markedly raised BP in $\mathrm{Lnk}^{-/-}$mice. Moreover, these results explain why conditions such as atherosclerosis, diabetes, and obesity, all of which are associated with systemic inflammation, do not uniformly raise BP, but likely sensitize individuals to developing hypertension.

In keeping with the above, it is interesting to note that Guyton and colleagues established the concept of the renal pressure natriuresis curve as a major mechanism of BP control (16). Experiments from their group and others suggested that it is impossible to sustain hypertension in a normal animal with a normal kidney because an elevated pressure elicits a diuresis and natriuresis, returning pressure to normal. Guyton suggested that the pressure natriuresis curve could be altered by several factors, including increased sympathetic tone, vasoconstriction, and humoral factors. Our current results and other recent studies suggest that inflammation is likely to be another factor that can shift the renal function curve and predispose to hypertension. To assess this concept, we performed a sodium challenge study in WT and $L n k^{-/-}$ mice. In response to an exogenous injection of normal saline equal to $10 \%$ of body weight, $\mathrm{Lnk}^{-/-}$mice retained $40 \%$ of the injected volume and excreted $50 \%$ less sodium, indicating that the ability of their kidneys to excrete a sodium and volume load is impaired at baseline (Figure 4, $\mathrm{H}$ and $\mathrm{I}$ ). In spite of this impairment in renal function, compensatory regulatory mechanisms are able to maintain a normal BP at baseline, but a "second hit," such as Ang II (even a normally subpressor dose of Ang II), is able to elevate BP (Figure 1, C and D).

LNK is highly expressed in all hematopoietic lineages and endothelial cells as well as in other stromal tissues, such as the testis, brain, and muscle. Most of the previously reported phenotypes of $\mathrm{Lnk}^{-/-}$mice, however, involve the hematopoietic compartment (17). In keeping with this, our BM transplantation experiments show that the absence of LNK in hematopoietic cells reproduces the prohypertensive phenotype seen in mice with a global deficiency of LNK. Interestingly, mice lacking only somatic LNK exhibited an intermediate elevation of BP, indicating that somatic LNK also contributes modestly to BP regulation (Figure 6B). We further analyzed the $\mathrm{T}$ cell infiltration into the kidneys and aorta of these mice by flow cytometry and measured 24-hour urinary albumin. We found that while loss of LNK in hematopoietic cells is primarily responsible for renal/vascular inflammation and hypertension, both hematopoietic and somatic LNK contribute to glomerular injury (Figure 6, D-F). We speculate that the modest BP elevation and albuminuria are due to loss of LNK in endothelial cells. LNK functions as a negative regulator of TNF signaling in endothelial cells. LNK has been shown to downregulate VCAM-1 and E-selectin induced by TNF- $\alpha$. In addition, LNK has been shown to upregulate eNOS protein and phosphorylation via a PI3K/Akt-dependent pathway (5). Endothelial NOS (eNOS) is an important downstream target of this pathway (5), and it is conceivable that the absence of LNK reduces eNOS activation. Consistent with this, we observed decreased NO levels from vessels of Lnkdeficient mice (Figure 5, I and J). Nevertheless, the striking result of the BMT experiment is that loss of LNK in hematopoietic cells is the main driver of Ang II-induced hypertension.

Our studies of cytokine production by $\mathrm{Lnk}^{-/-}$cells provide insight into a potential role of IFN- $\gamma$ in hypertension. We found that Lnk deficiency increases production of this proinflammatory cytokine, particularly by $\mathrm{CD}^{+} \mathrm{T}$ cells, both at baseline and in response to Ang II infusion (Figures 7 and 8). We found higher numbers of $\mathrm{CD}^{+} \mathrm{IFN}-\gamma^{+}$cells ( $\mathrm{T}_{\mathrm{C}} 1$ cells) in the spleen and kidneys of $\mathrm{Lnk}^{-/-}$mice, especially after Ang II infusion (Figures 7 and 8). This finding is in agreement with a recent study by Katayama et al. (18) in which Lnk deficiency in mice was associated with enhanced IFN- $\gamma$-producing $\mathrm{CD}^{+} \mathrm{T}$ cells in the spleen, mesenteric lymph nodes, and intestinal lamina propria that contributed to intestinal pathology resembling human celiac disease, another disorder that is associated with the same LNK polymorphism that is associated with hypertension.

The role of IFN- $\gamma$ in relation to various hypertensive stimuli has been mixed. Marko et al. (19) found that while IFN- $\gamma$ receptor-deficient mice exhibited reduced cardiac hypertrophy and decreased renal inflammation and tubulointerstitial damage compared with WT mice when infused with Ang II, there was no change in BP. However, they used a slightly different mouse model and a very high dose of Ang II (approximately twice the dose that we used). We found that IFN- $\gamma$ deficiency resulted in blunted hypertension in response to Ang II infusion (Figure 9). Our findings are in agreement with a study by Garcia et al. (20) in which IFN- $\gamma$ deficiency protected against hypertension in a mouse model of uninephrectomy when combined with aldosterone infusion and salt feeding.

The particular SNP that has been associated with hypertension and other cardiovascular disorders, rs3184504, results in a substitution of tryptophan for arginine at position 262 in the pleckstrin homology domain. This domain is thought to target LNK to the cell membrane. The minor allele for this SNP is highly prevalent in the population, with an estimated frequency of $48 \%$. There is evidence that individuals with this polymorphism may be protected against bacterial infection, which evolutionarily would be a strong driving force for selection of this SNP and thus the high frequency of this polymorphism (21). It thus appears that an unfortunate consequence of this evolutionary selection for genes that activate the immune system is development of autoimmune and cardiovascular diseases later in life, beyond the reproductive years.

Our model was an extreme case of total loss of LNK. Presumably, the human LNK polymorphisms, many of which are missense mutations, result in milder phenotypes due to partial mislocation and/or altered binding (and therefore signaling) with other proteins. Thus, we also examined heterozygous $L n k^{+/}$mice, which, 
although not a perfect model of human LNK polymorphisms, offer insights into the role of partial Lnk deficiency. Interestingly, we found that loss of even $1 \mathrm{LNK}$ allele is sufficient to raise BP and result in renal inflammation/injury (Supplemental Figure 4).

In conclusion, the intracellular adaptor molecule LNK serves as a "brake" to limit hypertension and the associated inflammatory response and is therefore a potential therapeutic target for hypertension and other autoimmune and cardiovascular disorders.

\section{Methods}

Animals and BP measurement. WT mice, either C57BL/6J (CD45.2) or SJL (CD45.1), and IFN- $\gamma$-deficient mice (Ifng ${ }^{-/}$) on a C57BL/6J background were purchased from Jackson Laboratories. Lnk-deficient mice $\left(L n k^{--}\right)$on a C57BL/6J background were generated as previously described (22). These mice were backcrossed with C57BL/6J more than 10 times. At approximately 10 to 12 weeks of age, osmotic minipumps (Alzet, model 2002 or 2004) were implanted subcutaneously for infusion of Ang II (490 or $140 \mathrm{ng} / \mathrm{kg} / \mathrm{min}$ ) or vehicle (sodium chloride/acetic acid solution) for 2 to 4 weeks depending on the experiment. BP was measured noninvasively using tail cuff or invasively using carotid radiotelemetry as previously described (7). After telemetry implantation, mice were allowed to recover for 10 days prior to placement of osmotic minipumps. Mice were sacrificed at the end of all experiments by $\mathrm{CO}_{2}$ inhalation.

Immunohistochemistry. Formalin-fixed, paraffin-embedded sections of renal cortex and medulla from WT C57BLl/6J or $\mathrm{Lnk}^{-1-}$ mice treated with 2 weeks of vehicle or Ang II were cut at 5 microns. For CD3 staining, slides were baked for 15 minutes at $60^{\circ} \mathrm{C}$. Antigen retrieval was performed using Epitope Retrieval Solution 2 (EDTA based proprietary reagent, Leica Microsystems) for 20 minutes. Goat anti-mouse CD3 (Santa Cruz Biotechnology Inc.) primary antibody was applied, followed by a biotinylated goat secondary antibody and then a tertiary labeled streptavidin. For F4/80 staining, slides were baked for 60 minutes at $60^{\circ} \mathrm{C}$. Antigen retrieval was performed on the Leica Bondmax platform (Leica Microsystems) using proteinase $\mathrm{K}$ (Dako USA; S302030-2) for 5 minutes. Rat anti-mouse F4/80 primary antibody (clone CI-A3-1, Novus Biologicals; NB600-404) was applied for 60 minutes, followed by a rabbit anti-rat secondary antibody and then a tertiary anti-rabbit polymer. For both CD3 and F4/80 staining, endogenous peroxidase was blocked using 3\% hydrogen peroxide. Slides were then stained with DAB chromogen and counterstained with hematoxylin for visualization.

Flow cytometry of renal, aortic, and splenic leukocytes. Single-cell suspensions of each organ were prepared as follows. Briefly, both kidneys from each mouse were mechanically dissociated using a single gentleMACS C tube dissociator system (Miltenyi Biotec) followed by incubation at $37^{\circ} \mathrm{C}$ for 20 minutes with collagenase $\mathrm{D}(2 \mathrm{mg} / \mathrm{ml})$ and DNAse I $(100 \mu \mathrm{g} / \mathrm{ml})$ in RPMI 1640 medium with 5\% FBS. Thoracic aortas with surrounding perivascular fat were minced with fine scissors and digested with $1 \mathrm{mg} / \mathrm{ml}$ collagenase A, $1 \mathrm{mg} / \mathrm{ml}$ collagenase $\mathrm{B}$, and $100 \mu \mathrm{g} / \mathrm{ml}$ DNAse I in RPMI 1640 medium with 5\% FBS for 30 minutes at $37^{\circ} \mathrm{C}$, with intermittent agitation. Spleens were ground and filtered through a $70-\mu \mathrm{m}$ cell strainer. The rbc were lysed using rbc lysis buffer (eBioscience). Tissue homogenates were filtered through a $70-\mu \mathrm{m}$ cell strainer. Kidney samples were subjected to Percoll gradient centrifugation by resuspension in 36\% Percoll (Amersham Pharmacia Biotech), gently overlaid onto $72 \%$ Percoll, and cen- trifuged at $1,000 \mathrm{~g}$ for 20 minutes at $4^{\circ} \mathrm{C}$. Cells were isolated from the Percoll interface and washed in cold PBS. Single-cell suspensions $(1 \times$ $10^{6}$ cells) were stained for flow cytometry after blocking of Fc receptors with CD16/CD32 for 20 minutes at $4^{\circ} \mathrm{C}$ (BD Biosciences, clone 2.4G2). Antibodies used for flow cytometry were as follows: Brilliant Violet 510-conjugated (BV510) anti-CD45 antibody (BioLegend, clone 30-F11), peridinin chlorophyll protein-cyanin-5.5-conjugated (PerCP-Cy5.5) anti-CD3 antibody (BioLegend, clone 17A2), phycoerythrin-cyanin-7-conjugated (PE-Cy7) anti-CD8 antibody (BioLegend, clone 53-6.7), allophycocyanin-Hilite-7-conjugated (APC-H7) antiCD4 antibody (BD Biosciences, clone GK1.5), and Alexa Fluor 488conjugated anti-F4/80 antibody (BioLegend, clone BM8). For live/ dead staining, 7-aminoactinomycin-D (7-AAD) (eBioscience) was added to the cells just prior to analysis on a BD FACSCanto II system. Analysis was performed using BD FACSDiva software (BD Biosciences). Gates were set using fluorescence minus one (FMO) controls. All lymphocyte subpopulations $\left(\mathrm{CD}^{+}, \mathrm{CD}^{+}\right.$, and $\left.\mathrm{CD}^{-} \mathrm{CD} 8^{-}\right)$were quantified within the $\mathrm{CD}^{+}$gate. The absolute number of infiltrating cells of each type was calculated by dividing the number of each population by the number of live cells obtained during flow cytometry (after exclusion of debris and dead cells) and then multiplying by the total number of live cells counted on a hemocytometer before staining (using trypan blue exclusion). Results are expressed as number of cells per 2 kidneys, per thoracic aorta, or per spleen. In some experiments, we added a known quantity of calibration (counting) beads to the sample (CountBright Absolute Counting Bead, Life Technologies) and used the bead count obtained during flow cytometry to normalize the results back to the original sample.

Intracellular staining for IFN- $\gamma$-producing lymphocytes from spleen and kidneys. Spleen and kidney single-cell suspensions were obtained as described above, and $1 \times 10^{6}$ cells were resuspended in RPMI medium supplemented with 5\% FBS and stimulated with $2 \mu \mathrm{l}$ of BD Leukocyte Activation Cocktail (ionomycin and PMA along with the Golgi inhibitor, brefeldin A) at $37^{\circ} \mathrm{C}$ for 5 hours. Cells were washed and stained first with LIVE/DEAD Fixable Violet dead cell stain (Invitrogen). The following surface antibodies were then added for 30 minutes: BV510-conjugated anti-CD45 antibody (clone 30-F11), PerCP-Cy5.5-conjugated anti-CD3 antibody (BioLegend, clone 17A2), PE-Cy7-conjugated anti-CD8 antibody (BioLegend, clone 53-6.7), and APC-H7-conjugated anti-CD4 antibody (BD Biosciences, clone GK1.5). Intracellular staining was then performed with the BD Cytofix/Cytoperm Plus fixation/permeabilization solution kit following the manufacturer's instructions (BD Biosciences) and using FITCconjugated anti-IFN- $\gamma$ antibody (eBioscience, clone XMG1.2). Results are presented as total number of IFN- $\gamma^{+}$cells among the $\mathrm{CD}^{+} \mathrm{CD}^{+}$, $\mathrm{CD}^{+}{ }^{+} \mathrm{CD} 8^{+}$, or $\mathrm{CD}^{+}{ }^{+} \mathrm{CD} 4^{-} \mathrm{CD}^{-}$(double negative) cell populations per spleen or per 2 kidneys.

Measurements of renal superoxide levels. Superoxide levels were measured from $3 \times 3 \times 1 \mathrm{~mm}$ renal cortical or medullary segments by quantifying the formation of 2-hydroxyethidium from DHE by HPLC. This product specifically reflects the reaction of superoxide with DHE as previously validated (23). For superoxide detection in kidney sections, frozen 30- $\mu \mathrm{m}$-thick kidney sections of WT or $\mathrm{Lnk}^{-/-}$mice infused with vehicle (sham) or Ang II (490 ng/ $\mathrm{kg} / \mathrm{min}$ ) for 2 weeks were incubated with DHE $(20 \mu \mathrm{M})$ in PBS for 30 minutes at $37^{\circ} \mathrm{C}$ in a humidified chamber protected from light. Specificity of staining was confirmed by ablation of the signal by preincubation of the sections 
with $300 \mathrm{U} / \mathrm{ml}$ superoxide dismutase. Samples were examined with an LSM710 confocal microscope (Zeiss). Specific measurements of superoxide were assessed via fluorescence signal at 530 to $560 \mathrm{~nm}$ using excitation at $405 \mathrm{~nm}$.

Measurements of urinary excretion of albumin, nephrin, and NGAL. Albumin, nephrin, and NGAL were measured from 24-hour urine samples. Mice were placed in metabolic cages for 24 hours for acclimatization, followed by 24 hours for urine collection. Albumin and nephrin concentrations were determined with ELISA kits from Exocell, and NGAL was determined with an ELISA kit from R\&D. All concentrations were multiplied by total urine volume to obtain the daily excretion rate.

qRT-PCR for NGAL. Total RNA was extracted from renal tissues using TRIzol reagent (Life Technologies). Reverse transcription was performed using a high-capacity cDNA reverse transcription kit (Applied Biosystems). qRT-PCR was performed using the TaqMan gene expression assay system (Applied Biosystems). The probe used was Mm01324470_m1 (mouse Lipocalin-2 [LCN2]), also known as NGAL (Invitrogen Life Technologies). Probes for GAPDH (Life Technologies) were used as endogenous controls. Gene expression values were calculated based on the comparative $\mathrm{Ct}$ normalized to the expression values of GAPDH mRNA and displayed as fold induction relative to control.

Saline challenge study. To examine the ability of mice to excrete water and sodium in response to a saline challenge, animals were briefly anesthetized with isoflurane in a specialized chamber and then injected intraperitoneally with a volume of normal saline (prewarmed to $37^{\circ} \mathrm{C}$ ) equal to $10 \%$ of their body weight. After mice had recovered from the anesthesia, urine in the bladder was evacuated by mild suprapubic compression, and the mice then were placed in a metabolic cage for the subsequent 4 hours. The volume of the excreted urine was accurately recorded and presented as a percentage of the volume injected. Sodium concentration was measured in the urine with a flame photometer (Eppendorf EFOX 5053).

Measurements of vascular reactivity and NO levels. Isometric tension studies of aortic rings were performed using 2-mm segments of mouse thoracic aortas dissected free of perivascular fat. Studies were performed in a small vessel horizontal wire myograph (Danish Myo Technology, models $610 \mathrm{M}$ and $620 \mathrm{M}$ ) containing physiological salt solution composed of $118 \mathrm{mM} \mathrm{NaCl}, 4.7 \mathrm{mM} \mathrm{KCl}, 1.2 \mathrm{mM} \mathrm{MgSO}_{4}, 1.2$

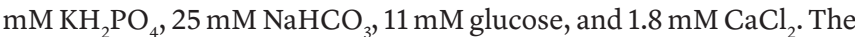
isometric tone of each vessel was recorded using LabChart Pro v7.3.7 (AD Instruments). The vessels were equilibrated over a 2-hour period by heating and stretching the vessels to an optimal baseline tension of 36 millinewtons before contracting them with 3 cycles of $60 \mathrm{mM}$ $\mathrm{KCl}$. Endothelial-dependent and -independent vascular relaxations were tested after preconstriction with phenylephrine $(1 \mu \mathrm{M})$. Once the vessels had reached a steady state of contraction, increasing concentrations of vasodilatory agents (acetylcholine or nitroglycerine) were administered as indicated, and the response to each concentration of drug was recorded. Calcium ionophore-stimulated NO production in 2-mm aortic segments was measured by electron spin resonance using the colloid probe $\mathrm{Fe}^{2+}$ diethyldithiocarbamate $\left(\mathrm{Fe}[\mathrm{DETC}]_{2}\right.$ ) as previously described (24).

BMT. Two weeks prior to BMT, 6-week-old $\mathrm{Lnk}^{-/-}$mice (on a CD45.2 background) and WT SJL mice (on a CD45.1 background) were transferred to sterile cages and fed sterile chow and acidified water ( $\mathrm{pH}$ 2.0) containing $1 \mathrm{mg} / \mathrm{ml}$ of sulfamethazine- $\mathrm{Na}^{+}$(SigmaAldrich) and $0.2 \mathrm{mg} / \mathrm{ml}$ of trimethoprim (Sigma-Aldrich) for prophylaxis. On the day of BMT, mice were lethally irradiated with a dose of 10 Gy 4 hours prior to BMT via a ${ }^{137} \mathrm{Cs}$ irradiator (J. L. Shepherd and Associates). BM cells from pooled femurs and tibias collected from 1 mouse were used to reconstitute the marrows of 2 mice $\left(20 \times 10^{6}\right.$ cells each). For example, cells from $1 \mathrm{Lnk}^{-/-}$mouse were injected via tail vein using a 25-gauge needle into another $\mathrm{LnK}^{-1-}$ mouse and an SJL mouse. The mice were then housed for 8 weeks to allow engraftment of the BM. Successful engraftment was confirmed upon sacrifice by flow cytometry of peripheral blood cells (after rbc lysis) using fluorescein isothiocyanate BV510-conjugated anti-CD45.2 antibody (BioLegend, clone 104) and Pacific blue-conjugated anti-CD45.1 antibody (BioLegend, clone A20).

Cytokine analysis. Splenic $\mathrm{CD}^{+}$or $\mathrm{CD}^{+} \mathrm{T}$ cells from WT C57BL/6J (WT) or $\mathrm{Lnk}^{-/-}$mice treated with 2 weeks of vehicle or Ang II were purified by negative selection using either a mouse $\mathrm{CD} 4^{+}$or $\mathrm{CD}^{+} \mathrm{T}$ cell isolation kit (Miltenyi Biotec). $\mathrm{CD} 4^{+}$or $\mathrm{CD} 8^{+} \mathrm{T}$ cells were cultured at $1 \times 10^{6}$ cells $/ \mathrm{ml}$ on anti-CD3 plates (BD Biosciences) with anti-CD28 $(2 \mu \mathrm{g} / \mathrm{ml})$ antibodies for 48 hours in RPMI 1640 medium supplemented with $2 \mathrm{mM}$ L-glutamine, $50 \mu \mathrm{M}$ 2-mercaptoethanol, heat-inactivated FBS (10\%), $10 \mu \mathrm{g} / \mathrm{ml}$ streptomycin, and $100 \mathrm{U} / \mathrm{ml}$ penicillin. Culture medium was supplemented with IL-2 (100 U/ml). Cytokines (IL-17A, IFN- $\gamma$, and TNF- $\alpha$ ) released into the media were detected using xMAP Luminex cytokine detection technology (Luminex 100/200 System).

Statistics. Data are expressed as mean \pm SEM. BPs were analyzed by ANOVA with repeated measures, 2-way ANOVA, or Student's $t$ test at specific time points. When comparing 2 groups, 1-tailed Student's $t$ test was used. For comparisons involving a $2 \times 2$ design (i.e., WT or $\mathrm{Lnk}^{-/}$mice exposed to vehicle or Ang II), 2-way ANOVA was used, and the $P$ value for each factor as well as the interaction of both factors is reported. When individual comparisons were made within this $2 \times 2$ design, Newman-Keuls or Holm-Sidak post-hoc tests were employed. For the flow cytometry and albuminuria experiments in the BM-transplanted mice, 1-way ANOVA with Holm-Sidak post-hoc test was used, with each group compared with the control SJL/SJL group. $P<0.05$ was considered significant.

Study approval. All animal procedures were approved by Vanderbilt University's Institutional Animal Care and Use Committee, and mice were housed and cared for in accordance with the Guide for the Care and Use of Laboratory Animals (National Academies Press. Revised 2010).

\section{Acknowledgments}

This work was supported by American Heart Association fellowship 14POST20420025 (to M.A. Saleh), NIH grants HL105294 and HL039006, Program Project grants P01 HL58000 and GM015431 (to D.G. Harrison), and NIH grant K08HL121671 and a Vanderbilt Physician Scientist Development Award (to M.S. Madhur).

Address correspondence to: Meena S. Madhur, Clinical Pharmacology, Cardiovascular Medicine, 2215 Garland Avenue, P415D Medical Research Building IV, Nashville, Tennessee 372326601, USA. Phone: 615.875.3273; E-mail: meena.madhur@ vanderbilt.edu. 
1. Chobanian AV. Shattuck Lecture. The hypertension paradox - more uncontrolled disease despite improved therapy. N EnglJMed. 2009;361(9):878-887.

2. Jermendy G, et al. Effect of genetic and environmental influences on cardiometabolic risk factors: a twin study. Cardiovasc Diabetol. 2011;10:96.

3. Mitchell GF, et al. Heritability and a genomewide linkage scan for arterial stiffness, wave reflection, and mean arterial pressure: the Framingham Heart Study. Circulation. 2005;112(2):194-199.

4. Levy D, et al. Evidence for a gene influencing blood pressure on chromosome 17. Genome scan linkage results for longitudinal blood pressure phenotypes in subjects from the Framingham heart study. Hypertension. 2000;36(4):477-483.

5. Devalliere J, Charreau B. The adaptor Lnk (SH2B3): an emerging regulator in vascular cells and a link between immune and inflammatory signaling. Biochem Pharmacol. 2011;82(10):1391-1402.

6. Guzik TJ, et al. Role of the T cell in the genesis of angiotensin II induced hypertension and vascular dysfunction.JExp Med.2007;204(10):2449-2460.

7. Madhur MS, et al. Interleukin 17 promotes angiotensin II-induced hypertension and vascular dysfunction. Hypertension. 2010;55(2):500-507.

8. Wenzel P, et al. Lysozyme M-positive monocytes mediate angiotensin II-induced arterial hypertension and vascular dysfunction. Circulation.
2011;124(12):1370-1381.

9. Coffman TM. Under pressure: the search for the essential mechanisms of hypertension. Nat Med. 2011;17(11):1402-1409.

10. Lee DL, et al. Angiotensin II hypertension is attenuated in interleukin-6 knockout mice. Am JPhysio Heart Circ Physiol. 2006;290(3):H935-H940.

11. Crowley SD, Song YS, Lin EE, Griffiths R, Kim HS, Ruiz P. Lymphocyte responses exacerbate angiotensin II-dependent hypertension. Am J Physiol Regul Integr Comp Physiol. 2010;298(4):R1089-R1097.

12. Lob HE, et al. Induction of hypertension and peripheral inflammation by reduction of extracellular superoxide dismutase in the central nervous system. Hypertension. 2010;55(2):277-283.

13. Araujo M, Wilcox CS. Oxidative stress in hypertension: role of the kidney. Antioxid Redox Signal. 2014;20(1):74-101.

14. Trott DW, et al. Oligoclonal CD8 ${ }^{+} \mathrm{T}$ cells play a critical role in the development of hypertension. Hypertension. 2014;64(5):1108-1115.

15. Mattson DL, Lund H, Guo C, Rudemiller N, Geurts AM, Jacob H. Genetic mutation of recombination activating gene 1 in Dahl saltsensitive rats attenuates hypertension and renal damage. Am J Physiol Regul Integr Comp Physiol. 2013;304(6):R407-R414.

16. Hall JE, Guyton AC, Brands MW. Pressure-volume regulation in hypertension. Kidney Int Suppl. 1996;55:S35-S41.
17. Gery S, Koeffler HP. Role of the adaptor protein LNK in normal and malignant hematopoiesis. Oncogene. 2013;32(26):3111-3118.

18. Katayama $\mathrm{H}$, et al. Lnk prevents inflammatory CD8 T-cell proliferation contributes to intestinal homeostasis. Eur J Immunol. 2014;44(6):1622-1632.

19. Marko L, et al. Interferon- $\gamma$ signaling inhibition ameliorates angiotensin II-induced cardiac damage. Hypertension. 2012;60(6):1430-1436.

20. Garcia AG, et al. Interferon- $\gamma$ ablation exacerbates myocardial hypertrophy in diastolic heart failure. Am J Physiol Heart Circ Physiol. 2012;303(5):H587-H596.

21. Zhernakova A, et al. Evolutionary and functional analysis of celiac risk loci reveals $\mathrm{SH} 2 \mathrm{~B} 3$ as a protective factor against bacterial infection. Am J Hum Genet. 2010;86(6):970-977.

22. Takaki S, et al. Control of B cell production by the adaptor protein lnk. Definition of a conserved family of signal-modulating proteins. Immunity. 2000;13(5):599-609.

23. Fink B, Laude K, McCann L, Doughan A, Harrison DG, Dikalov S. Detection of intracellular superoxide formation in endothelial cells and intact tissues using dihydroethidium and an HPLC-based assay. Am J Physiol Cell Physiol. 2004;287(4):C895-C902.

24. Dikalov S, Fink B. ESR techniques for the detection of nitric oxide in vivo and in tissues. Methods Enzymol. 2005;396:597-610. 